\title{
The use of Hagemann's Esters to prepare highly functionalized phenols and benzenes ${ }^{\S}$
}

\author{
George Majetich* and Scott Allen \\ Department of Chemistry, University of Georgia, Athens, Georgia USA 30602 \\ E-mail: majetich@chem.uga.edu
}

Dedicated to "Captain" James M. Cook on the occasion of his $65^{\text {th }}$ birthday ${ }^{\xi}$

DOI: http://dx.doi.org/10.3998/ark.5550190.0011.410

\begin{abstract}
Hagemann's esters can be converted into highly functionalized phenols or arenes. The systematic functionalization of Hagemann's ester derivatives permits the preparation of tri- and tetraalkylsubstituted phenols or tetra-, penta-, and hexaalkyl-substituted benzenes. Kotnis's aromatization procedure was found to be solvent dependent, and Suzuki couplings were found to be sensitive to steric hindrance. Wittig olefination and ortho-Claisen reactions were reliable means to introduce alkyl substituents at C-4 and/or C-5 positions, respectively. The acid-promoted dehydration of tertiary alcohol 46 to produce enone 47 , followed by its selective alkylation (cf. 48) is new.
\end{abstract}

Keywords: Hagemann's ester, tetraalkylphenols, pentaalkylbenzene, Suzuki coupling, regiospecific alkylations, aromatization

\section{Introduction}

Many naturally occurring and biologically active compounds contain a highly substituted benzene ring. ${ }^{1}$ While functionalization of benzene has been an active area of organic chemistry for more than 150 years, the number of strategies for preparing highly alkylated phenols ${ }^{2 a-c}$ and highly alkylated benzenes is limited. ${ }^{2 \mathrm{~d}-\mathrm{f}}$

In 1894, Hagemann ${ }^{3 a}$ treated two equivalents of ethyl acetoacetate 1 with one equivalent of diiodomethane and excess sodium methoxide to form glutamate diester 2; further treatment of 2 with base and heat produced cyclic ester 3 (Scheme 1). Although the initial structure of 3 required revision, ${ }^{3 \mathrm{~b}}$ these cyclohexenone derivatives became known as "Hagemann's esters." One year after Hagemann's synthesis of 3, Knoevenagel improved its preparation by coupling $\mathbf{1}$ with formaldehyde to generate Michael acceptor 4 in situ, which reacts with a second molecule of $\mathbf{1}$ to yield diketone $\mathbf{2},{ }^{4}$ which in turn, undergoes intramolecular aldol reaction to produce 
cyclic alcohol 7. The mechanism of the formation of Hagemann's ester has been the subject of extensive investigation, ${ }^{5}$ but it was not until 1984 when Hoye and co-workers established that aldol 7 forms lactone 8, which loses carbon dioxide to form ester $3{ }^{6}$ Horning and co-workers developed conditions so that Knoevenagel's modification could be carried out in a single operation; ${ }^{7}$ this one-pot, tandem Knoevenagel/intermolecular Michael addition/intramolecular aldol reaction/intramolecular trans-esterification/decarboxylation sequence represents one of the earliest cascade reactions. ${ }^{8}$ A useful modification of Knoevenagel's general procedure was to employ an aldehyde (or a ketone) in the condensation step, ${ }^{9}$ which introduces one alkyl (or two alkyl) substituent(s) at the C-6 position (cf. $\mathbf{1} \rightarrow \mathbf{5} \rightarrow \mathbf{6} \rightarrow \mathbf{7} \rightarrow \mathbf{8} \rightarrow \mathbf{9}$ ). A comprehensive review of the synthetic utility and versatility of Hagemann's esters has recently been published. ${ }^{10}$

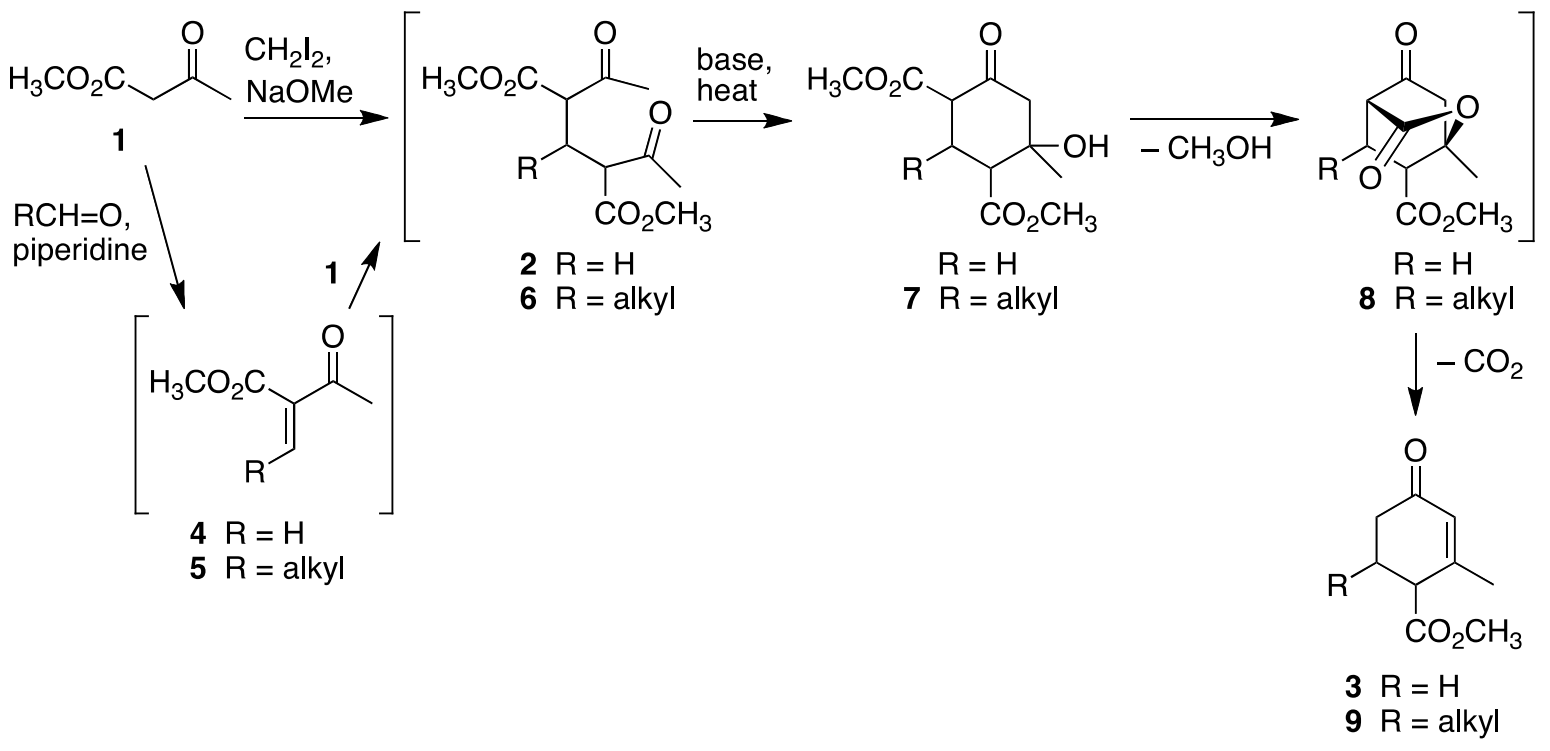

Scheme 1. The intermediates produced during a Hagemann's ester synthesis.

Hagemann's esters can undergo selective alkylation at three sites. In 1943, Smith and Rouvault reported that 3 undergoes alkylation exclusively at C-3 (cf. 10, Scheme 2). ${ }^{11}$ Many syntheses have utilized this alkylation, followed by saponification and decarboxylation, to prepare 2-alkyl-3-methyl-2-cyclohexenones. ${ }^{12}$ Once the C-3 position of Hagemann's ester is substituted, Dyier and coworkers found that a second alkyl substituent can be introduced at C-1 in high yield (cf. 11). ${ }^{13}$ The introduction of an alkyl group at C-5 (cf. 9) produces enone 12, which upon saponification and decarboxylation of the C-1 ester produces enone $\mathbf{1 3}$ having four different alkyl substituents. Substituted cyclohexenones are easily aromatized using palladium catalyzed dehydrogenation ${ }^{14}$ or by introducing a leaving group at C-5 followed by elimination and keto-enol tautomerization. ${ }^{15}$ If an alkyl group is introduced at C-6 while preparing the Hagemann's ester, the systematic introduction of alkyl substituents at C-1, C-3, and C-5 produces phenols with five different alkyl substituents (cf. 15). A structural feature common to all Hagemann's esters is the methyl group at C-2. A project in our labs required the preparation 
of a pentaalkyl-substituted phenol with a methyl substituent at C-2. This led us to explore the strategy generalized in Scheme 2. The results of this investigation are described herein.

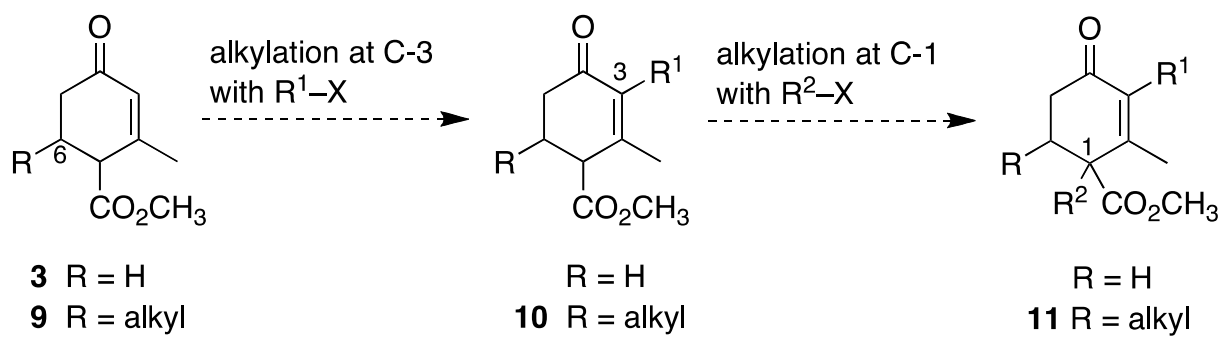

alkylation at $\mathrm{C}-5$ with $\mathrm{R}^{3}-\mathrm{X}$

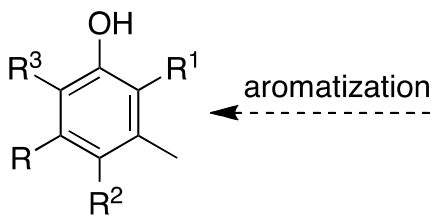<smiles>[R7]C1=C(C)C([R7])C([R])C([R])C1=O</smiles>

$\mathrm{R}=\mathrm{H}$

$13 \mathrm{R}=$ alkyl<smiles>[R]C1=C(C)C([R])(C(C)=O)C([R])C(=O)C1[R]</smiles>

$\mathrm{R}=\mathrm{H}$

$12 \mathrm{R}=\mathrm{alkyl}$

Scheme 2. Our alkylation strategy.

\section{Results and Discussion}

In 1990, Kotnis found that Hagemann's esters aromatized on treatment with iodine in refluxing methanol (Scheme 3). ${ }^{16}$ While a mechanism has not been proposed for this transformation, it seems reasonable that $p$-hydroxybenzoate 16 was formed by oxidation with one molecule of iodine. This oxidation produces hydrogen iodide in situ, which can protonate the solvent, methanol. The protonated methanol can either act itself as an electrophile in an $\mathrm{S}_{\mathrm{N}} 2$-displacement or it can form iodomethane in situ; either electrophilic species leads to $p$-methoxybenzoate 17.

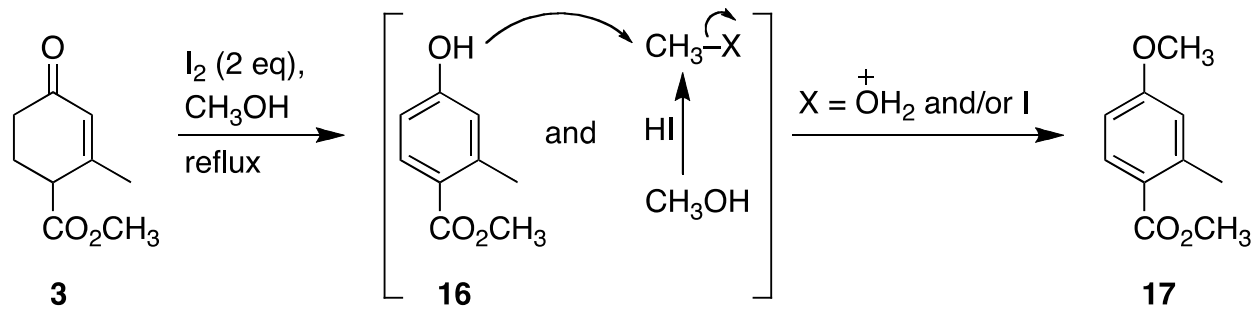

Scheme 3. Kotnis' conversion of Hagemann's ester into a $p$-methoxybenzoate. 
We believed that the use of $t$-butyl alcohol in the aromatization procedure would produce only $p$-hydroxybenzoate $\mathbf{1 6}$ because $t$-butyl alcohol is less likely to act like methanol. The treatment of Hagemann's ester 18, readily prepared by the procedure developed by McCurry and Singh, ${ }^{9 \mathrm{c}}$ with two equivalents of iodine in refluxing $t$-butyl alcohol gave $p$-hydroxybenzoate 19 in $60 \%$ yield (Scheme 4). The alkylation of Hagemann's esters 18 and 22 with methyl iodide produced esters 20 and 23, respectively. Ester 20 was aromatized in 65\% yield using iodine in refluxing $t$-butyl alcohol, but aromatization of $\mathbf{2 3}$ was slower and occurred in only a $34 \%$ yield.

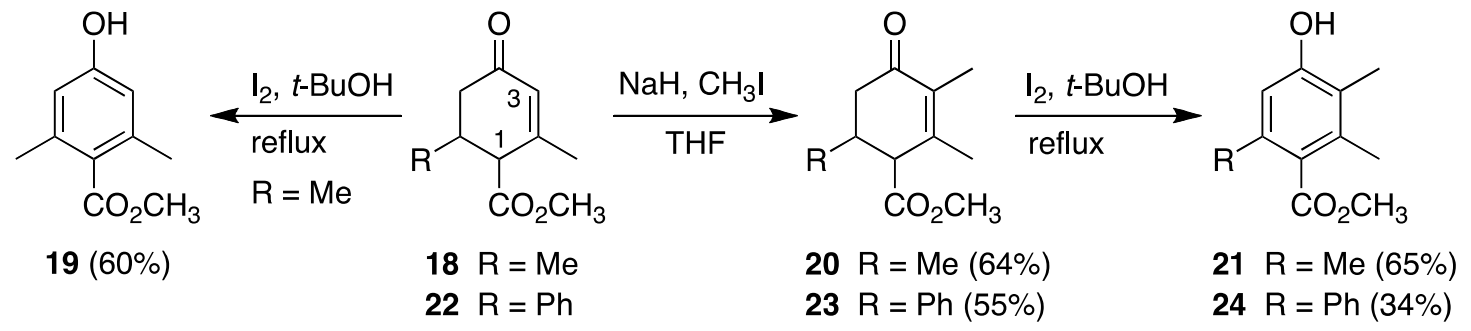

Scheme 4. Our modification of Kotnis's aromatization procedure.

The alkylation of an alkyl substituent at C-5 of a Hagemann ester is problematic. ${ }^{10}$ However, an allyl group can be easily introduced at the C-5 position of the appropriate phenol via an orthoClaisen rearrangement. ${ }^{17}$ For example, phenols 21 and $\mathbf{2 4}$ were converted smoothly into their allyl ethers $\mathbf{2 5}$ and 27, respectively, which were heated in diethylaniline to give phenols $\mathbf{2 6}$ and 28, respectively, in good yields (Scheme 5). This strategy allows to construct a fully functionalized phenol in a few steps with complete control of the substituents on the phenyl ring: (1) the C-2 methyl was installed during the synthesis of the Hagemann's ester; (2) the C-6 alkyl substituent was governed by the choice of aldehyde used in the ester synthesis; (3) the substituent at C-3 was dictated by the choice of the alkylating agent; and (4) even though the $o$ Claisen rearrangement introduces an allyl group at $\mathrm{C}-5$, the double bond can be isomerized to the styrenyl position and then oxidized to generate either an aldehyde or a carboxylic acid.

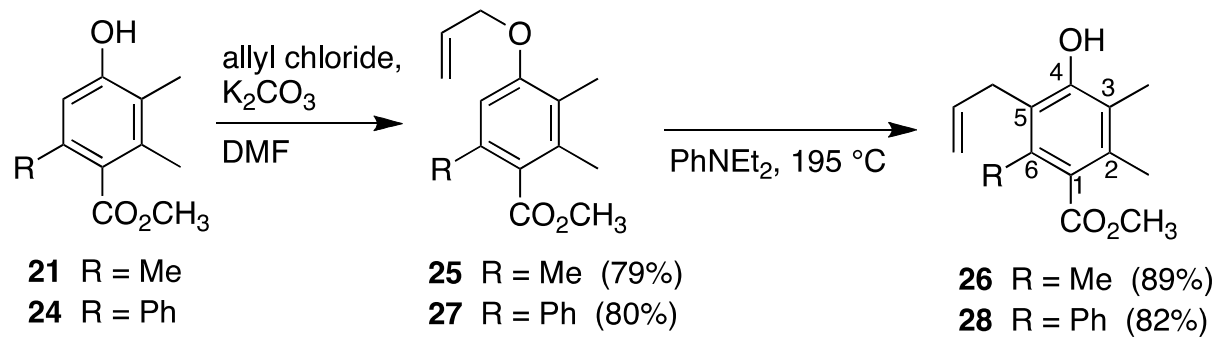

Scheme 5. Introduction of a substituent at C-5 via an ortho-Claisen rearrangement.

Since many synthetic targets may not require alkyl substituents at every position of an arene, a route for preparing phenols without the ester moiety at the C-1 position was studied. The ester 
moiety present in $\mathbf{1 8}$ and $\mathbf{2 0}$ is vinylogous to the enone and can undergo decarboxylation using the same conditions that apply to $\beta$-keto esters (Scheme 6). Accordingly, heating esters 18 and 20 to $145{ }^{\circ} \mathrm{C}$ in moist DMSO containing $\mathrm{LiCl}$ gave enones 29 and $\mathbf{3 1}$ in good yields. Refluxing enone 29 or $\mathbf{3 1}$ in ethylene glycol in the presence of $10 \% \mathrm{Pd} / \mathrm{C}$ (Horning's aromatization conditions $^{14}$ ) produced phenols $\mathbf{3 0}$ or $\mathbf{3 2}$, respectively.

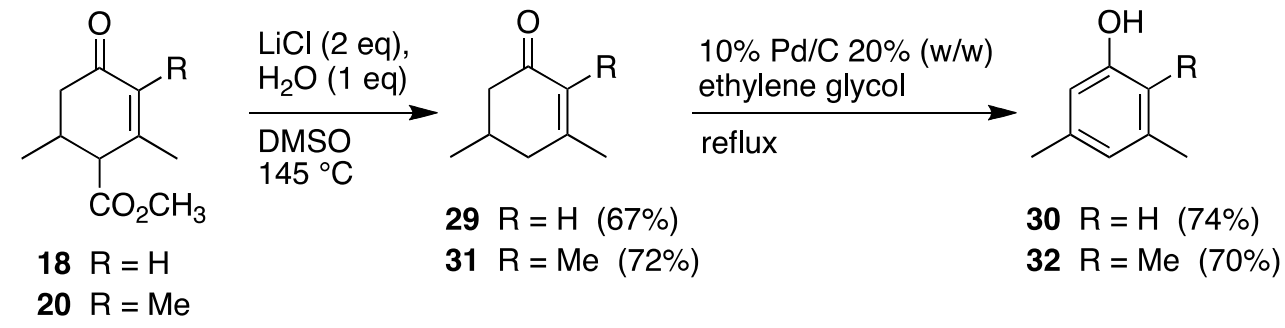

Scheme 6. Preparation of trisubstituted phenols.

Our efforts then turned toward the synthesis of 4-alkyl-substituted benzenes. In the Suzuki coupling reaction alkylboron reagents can be cross-coupled with aryl or vinyl halides ${ }^{18 a}$ and triflates ${ }^{18 \mathrm{~b}}$ by using a Pd catalyst. The application of this method to our substrates would allow for highly alkylated phenols to be converted into more functionalized arenes. For example, phenol 21 was converted into triflate 33 using pyridine and triflic anhydride (Scheme 7). Triflate 33 and the alkylborane formed by reacting 9-BBN with 1-octene were treated with $\mathrm{Pd}\left(\mathrm{PPh}_{3}\right)_{4}$, to produce arene 34 in $57 \%$ yield. Triflate 35 was generated from phenol $\mathbf{3 2}$ in $86 \%$ yield. Standard Suzuki coupling conditions gave benzene derivative $\mathbf{3 6}$ in $82 \%$ yield.

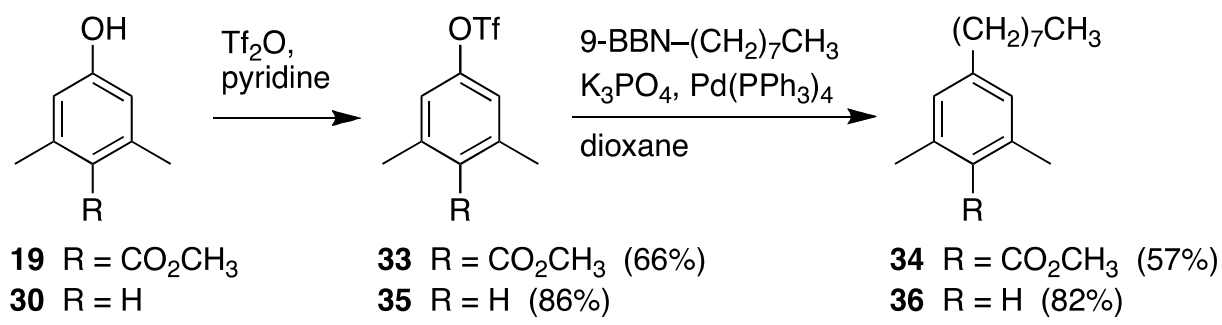

Scheme 7. Preparation of a tetra- or a pentasubstituted benzene.

Interestingly, an attempted Suzuki coupling of triflate 37 failed (Scheme 8), which suggests that substitution at the positions ortho to the triflate generates steric crowding that complicate the Suzuki coupling reaction. A search of the literature failed to find examples of successful Suzuki couplings between an aryl triflate with two ortho substituents under standard Suzuki conditions. 


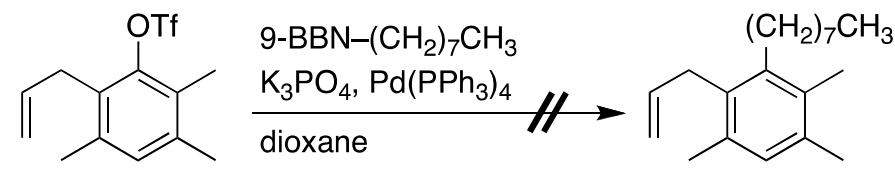

37

Scheme 8. Failure of the Suzuki coupling with sterically crowded triflates.

Traditional methods to functionalize the C-4 position were also investigated. For example, treatment of enone $\mathbf{2 9}$ and $\mathbf{3 1}$ with 1.3 equivalents of $n$-butyllithium gave tertiary alcohols $\mathbf{3 8}$ and 41, respectively (Scheme 9). Both alcohols rapidly dehydrated to produce methylenecyclohexenes. The formation of the exocyclic double bond was inconsequential as dienes 39 and $\mathbf{4 2}$ aromatized in good yield affording the polyalkyl-substituted benzenes $\mathbf{4 0}$ and $\mathbf{4 3}$, respectively.

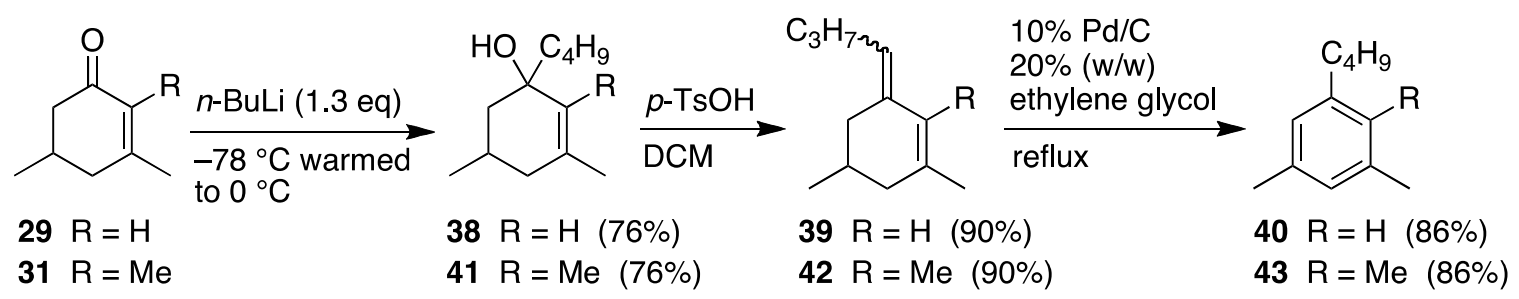

Scheme 9. Preparation of tetrasubstituted alkylbenzenes.

Methylenecyclohexenes similar to $\mathbf{3 9}$ and $\mathbf{4 2}$ can also be prepared by treating a substituted 2cyclohexenone with a Wittig reagent. For example, treatment of enone 29 with methylene triphenylphosphonium ylide produced a mixture of methylenecyclohexene $\mathbf{4 4}$ and cyclohexa-1,3diene $\mathbf{4 5}$, which produced mesitylene in $76 \%$ yield upon treatment with palladium (Scheme 10).

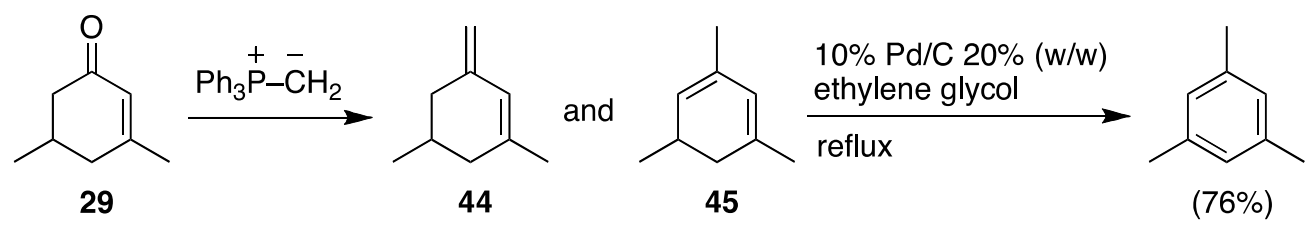

Scheme 10. Functionalization of 2-cyclohexenone using a Wittig/aromatization sequence. 


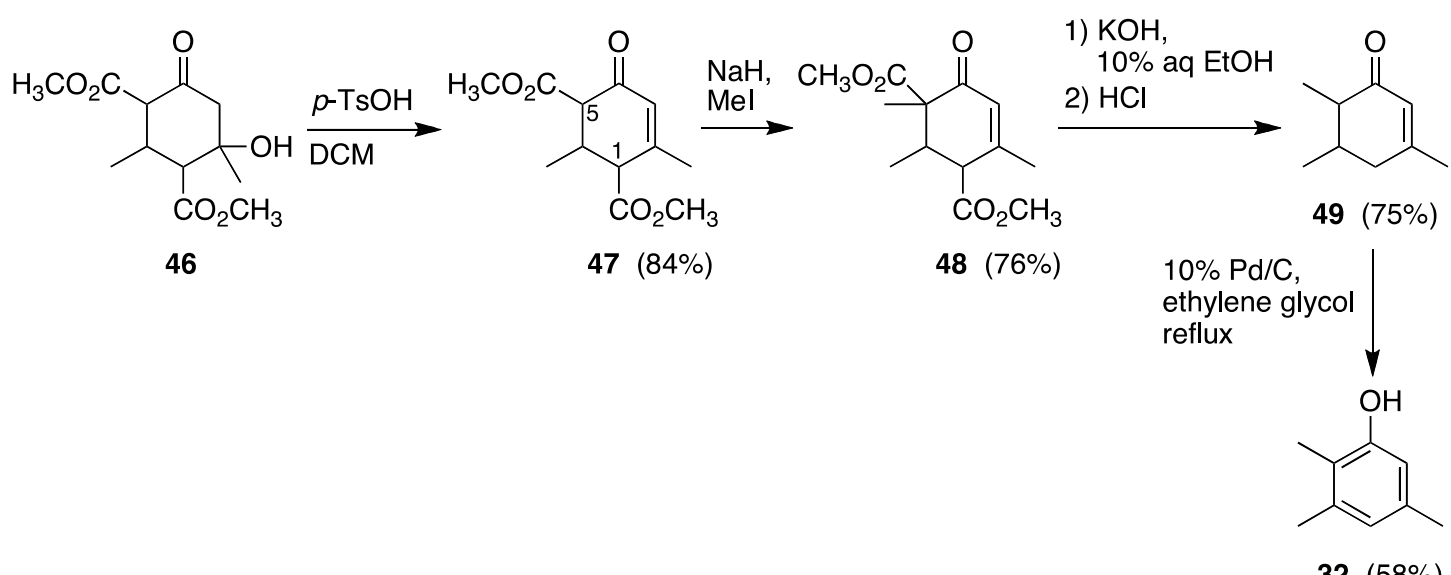

Scheme 11. Preparation of 2,3,5-trimethylphenol 32.

In contrast to the normal one-pot Hagemann's ester synthesis, careful monitoring of the reaction allowed us to stop the cascade of transformations at the tertiary alcohol 46 . Treating 46 with $p$-TsOH produced enone 47 , which retains the $\mathrm{C}-5$ ester. Although both the $\mathrm{C}-1$ and $\mathrm{C}-5$ methine positions are doubly activated, we predicted that the more accessible H-5 would be abstracted preferentially to form the C-4, C-5 enolate. When enone 47 was treated with sodium hydride and methyl iodide, only diester 48 was isolated (Scheme 11). In order to prove this structure, diester 48 was saponified and decarboxylated to give 3,5,6-trimethyl-2-cyclohexenone 49, which was then aromatized to produce phenol 32, which was synthesized earlier through a different route.

Another subtle advantage of diester 48 is that it can be alkylated at C-3 (cf. 50) and then decarboxylated to produce tetrasubstituted enone $\mathbf{5 1}$ (Scheme 12). The conversion of 51 into 1,2,4,5-tetramethylbenzene was straightforward. Treatment of enone $\mathbf{5 1}$ with DIBAL gave alcohol 52 in $81 \%$ yield. Dehydration of 52 using $p$-TsOH in DCM gave an inseparable mixture of isomeric dienes $\mathbf{5 3}$ and $\mathbf{5 4}$ which were aromatized to give 1,2,4,5-tetramethylbenzene $\mathbf{5 5}$.

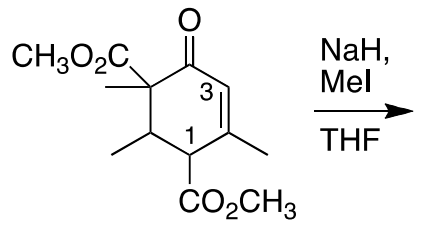

48

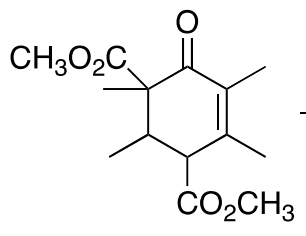

$50(80 \%)$

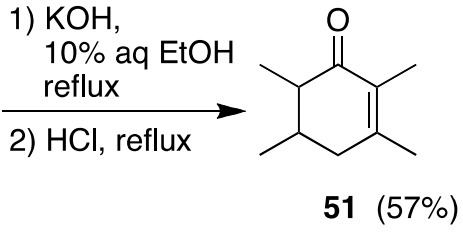

DIBAL

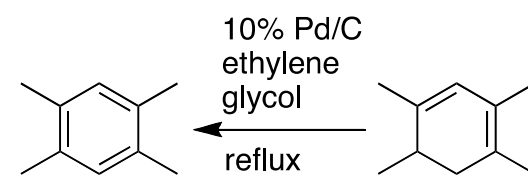

$55(84 \%)$
54

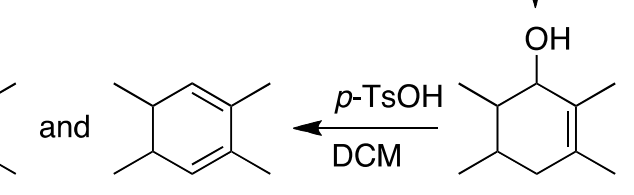

53

$52(81 \%)$

Scheme 12. Preparation of 1,2,4,5-tetramethylbenzene. 
The tetrasubstituted enone $\mathbf{5 1}$ could give pentasubstituted benzene derivatives (Scheme 13). Treatment of enone $\mathbf{5 1}$ with $n$-butyllithium gave tertiary alcohol 56, which was dehydrated under mildly acidic conditions to give diene 57. The aromatization of diene 57 was achieved by palladium-catalyzed dehydrogenation ${ }^{19}$ to give pentaalkylbenzene derivative $\mathbf{5 8}$.

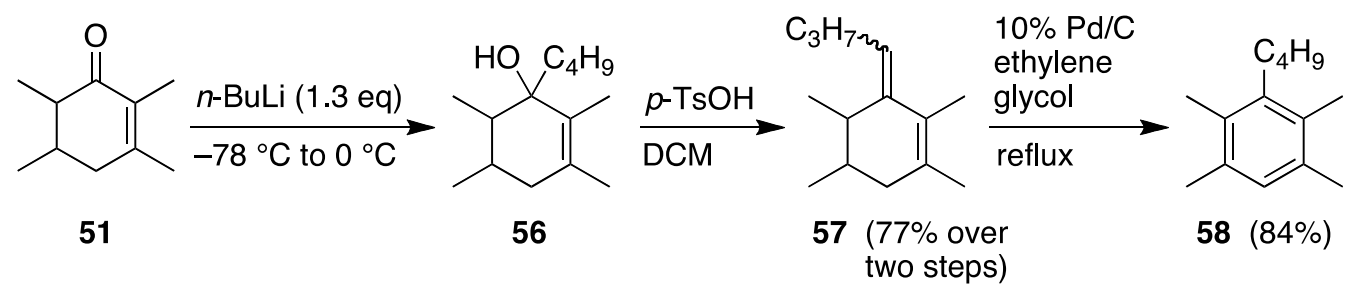

Scheme 13. Synthesis of 3-butyl-1,2,4,5-tetramethylbenzene 58.

Scheme 14 shows how hexamethylbenzene $\mathbf{6 0}$ could be synthesized based on the findings reported in this paper. The synthesis of whimsical hexasubstituted benzenes, such as $\mathbf{6 1}$, can be envisioned using this methodology.

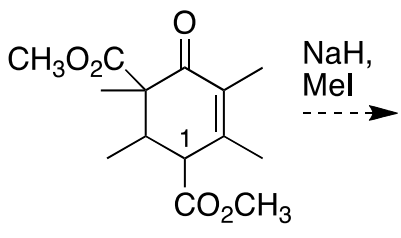

50

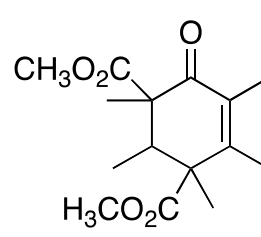

59
1) $\mathrm{KOH}$, aq $10 \% \mathrm{EtOH}$

2) $\mathrm{HCl}$

3) $\mathrm{MeLi}$

4) $\mathrm{Pd}-\mathrm{C}$

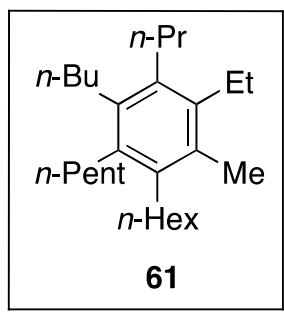

Scheme 14. The preparation of hexamethylbenzene.

In summary, we have shown that Hagemann's esters can be used to prepare polysubstituted phenols and benzene derivatives in a concise, completely regioselective fashion. In addition, we observed that although Suzuki coupling reactions can be used to convert complex phenols into complex benzene derivatives, triflates with two ortho substituents failed to couple. A substituent can be readily introduced at C-4 by using standard organometallic additions or Wittig reactions.

\section{Experimental Section}

General. Routine ${ }^{1} \mathrm{H}$ NMR spectra were determined in $\mathrm{CDCl}_{3}$ on either a Bruker $\mathrm{AC} 250$ instrument $\left({ }^{1} \mathrm{H}: 250 \mathrm{MHz} ;{ }^{13} \mathrm{C}: 62.9 \mathrm{MHz}\right)$ or a Bruker AC300 instrument $\left({ }^{1} \mathrm{H}: 300 \mathrm{MHz} ;{ }^{13} \mathrm{C}\right.$ : 75.5 MHz). Chemical shifts are reported relative to TMS. The data reported as integer numbers are accurate to within $\pm 10 \%$. Genuine effort was made to ensure that NMR spectra did not contain any solvent "impurities." All samples were "pure" by ${ }^{1} \mathrm{H}$ and ${ }^{13} \mathrm{C}$ NMR analysis. Infrared 
(IR) spectra were recorded as thin films between polished sodium chloride plates on a PerkinElmer FT-IR 1600. Electron impact mass spectra (EIMS) were recorded on a Finnigan 4000 spectrometer $(70 \mathrm{eV})$ and are expressed in $\mathrm{m} / \mathrm{z}$ units.

Anhydrous THF and diethyl ether were prepared by refluxing with, and distillation from sodium/benzophenone under a nitrogen atmosphere in a recycling still. Anhydrous DMF was prepared by refluxing over, and distillation from calcium hydride. All reactions were run under nitrogen using standard laboratory techniques for the exclusion of oxygen and moisture and were monitored by TLC analysis until the starting material was completely consumed. CAS numbers were provided for only a few compounds.

\section{General procedure A. Alkylation of Hagemann's esters}

$\mathrm{NaH}$ (1.1 molar equiv relative to the ester) was degreased with hexanes and the residual solvent was removed by vacuum. $\mathrm{NaH}$ was placed under nitrogen and cooled to $-15{ }^{\circ} \mathrm{C}$. Dry THF $(10$ $\mathrm{mL}$ ) was added to the NaH. The Hagemann's ester $(1.0 \mathrm{eq})$ in THF $(25 \mathrm{~mL})$ was added slowly to the stirred $\mathrm{NaH}$, after which the mixture was stirred at $-15^{\circ} \mathrm{C}$ for $1 \mathrm{~h}$. An alkyl halide (1.5 equiv) was then added and the reaction mixture was warmed to room temperature and stirred overnight. The reaction mixture was diluted with ether to four times the original volume. The organic layer was washed with water $(4 \times 25 \mathrm{~mL})$. The aqueous phase was extracted with ether $(3 \times 10 \mathrm{~mL})$. The organic extracts were combined, washed with brine, dried over anhydrous $\mathrm{MgSO}_{4}$, filtered, and then concentrated. The product was isolated by flash chromatography on silica gel. ${ }^{20}$

\section{General procedure B. Aromatization of alkylated Hagemann's esters}

The C-3-alkylated Hagemann ester (cf. 10) (1 eq) was dissolved in $t$-butyl alcohol $(150 \mathrm{~mL})$. Iodine ( 2 equiv) was added portionwise. The reaction mixture was refluxed, while maintaining the solvent level between $125 \mathrm{~mL}$ and $150 \mathrm{~mL}$. The reaction mixture was cooled and the solvent was removed by rotary evaporation. The resulting residue was taken up in ether $(200 \mathrm{~mL})$ and washed with water $(20 \mathrm{~mL})$, and $10 \%$ sodium thiosulfate $(3 \times 20 \mathrm{~mL})$. The ether layer was concentrated to one-third its original volume and was then extracted with $4 \% \mathrm{NaOH}_{(\mathrm{aq})}(4 \times 15$ $\mathrm{mL}$ ). The basic extract was then cooled to $0{ }^{\circ} \mathrm{C}$ using an ice bath and was acidified with $10 \%$ $\mathrm{HCl}_{(\mathrm{aq})}$. The acidified layer was then extracted with ether/ethyl acetate 1:1 $(3 \times 40 \mathrm{~mL})$. The organic extracts were combined, washed with brine, dried over anhydrous $\mathrm{MgSO}_{4}$, filtered, and then concentrated.

\section{General procedure C. Synthesis of allyl aryl ethers}

The phenol 21 (1.0 equiv) was dissolved in dry DMF (18 mL). Allyl chloride (1.4 equiv), potassium carbonate ( 2 equiv), and potassium iodide (catalytic amount) were added sequentially and the reaction mixture was stirred for $24 \mathrm{~h}$. The reaction mixture was diluted with ether (125 $\mathrm{mL})$ and washed with water $(3 \times 30 \mathrm{~mL})$. The aqueous phase was extracted with ether $(20 \mathrm{~mL})$, and the ethereal extracts were combined, washed with $10 \%$ aqueous cupric sulfate $(20 \mathrm{~mL})$ and brine $(10 \mathrm{~mL})$. The organic layer was dried over anhydrous $\mathrm{MgSO}_{4}$, filtered, and then 
concentrated. The Claisen rearrangement precursor was isolated using flash chromatography on silica gel.

\section{General procedure D. ortho-Claisen rearrangement}

The allyl aryl ether (1.0 equiv) was dissolved in $2 \mathrm{~mL}$ of $N, N$-diethylaniline. The reaction mixture was sealed in a thick-walled glass tube equipped with a Teflon screw top (Ace Glass) and was heated at $200{ }^{\circ} \mathrm{C}$ for $12 \mathrm{~h}$. The reaction mixture was cooled and diluted with ether to ten times its original volume. The organic phase was washed with cold $5 \% \mathrm{HCl}_{(\mathrm{aq})}(4 \times 5 \mathrm{~mL})$, and brine $(5 \mathrm{~mL})$. The organic phase was dried over anhydrous $\mathrm{MgSO}_{4}$, filtered, and then concentrated. The rearrangement product was isolated by flash chromatography on silica gel.

\section{General procedure E. Synthesis of triflates}

The phenol (1.0 equiv) was dissolved in pyridine $(0.4 \mathrm{~mL})$. The reaction mixture was cooled to 0 ${ }^{\circ} \mathrm{C}$. Triflic anhydride (1.1 equiv) was added dropwise, and the reaction mixture was stirred at room temperature for $20 \mathrm{~h}$. The reaction mixture was poured into water $(2 \mathrm{~mL})$ and ether $(25$ $\mathrm{mL})$ was added. The organic layer was washed with water $(3 \times 3 \mathrm{~mL})$ and brine $(3 \mathrm{~mL})$, and dried over anhydrous $\mathrm{MgSO}_{4}$, filtered, and then concentrated. The crude triflate was isolated via flash chromatography on silica gel.

\section{General procedure F. Suzuki coupling of triflates}

To a flask at $0{ }^{\circ} \mathrm{C}$ was added 9-BBN $(0.5 \mathrm{M}$ solution in THF, $1.1 \mathrm{mmol})$ and 1-octene (1.1 mmol). The mixture was warmed to room temperature and stirred at room temperature for $3 \mathrm{~h}$. Dioxane $(5 \mathrm{~mL}), \mathrm{K}_{3} \mathrm{PO}_{4}(1.5 \mathrm{mmol}), \mathrm{Pd}\left(\mathrm{PPh}_{3}\right)_{4}(0.025 \mathrm{mmol})$, and triflate $(1.0 \mathrm{mmol})$ were added and the resulting mixture was heated at $85{ }^{\circ} \mathrm{C}$ for $5 \mathrm{~h}$. The residual boron reagent was oxidized with $3 \mathrm{M} \mathrm{NaOAc}_{(\mathrm{aq})}(0.5 \mathrm{~mL})$ and $30 \% \mathrm{H}_{2} \mathrm{O}_{2}$ at room temperature for $1 \mathrm{~h}$. The reaction mixture was poured into water $(5 \mathrm{~mL})$ and diluted with ether $(40 \mathrm{~mL})$. The organic layer was washed with water $(3 \times 3 \mathrm{~mL})$ and brine $(3 \mathrm{~mL})$. The organic layer was dried over anhydrous $\mathrm{MgSO}_{4}$, filtered, and then concentrated. The coupled aromatic product was purified via flash chromatography on silica gel.

\section{General procedure G. Aromatization of 2-cyclohexen-1-ones}

To a solution of an alkylated 2-cyclohexen-1-one (1.0 equiv) in ethylene glycol $(6.0 \mathrm{~mL})$ at room temperature was added $10 \% \mathrm{Pd} / \mathrm{C}(100 \mathrm{mg} / 1 \mathrm{~g}$ of enone). The solution was refluxed for $6 \mathrm{~h}$. The solution was cooled to $50{ }^{\circ} \mathrm{C}$ and filtered to remove the catalyst, which was washed with hot ethyl acetate $(3 \times 15 \mathrm{~mL})$. The organic phases were combined, washed with water $(6 \times 10 \mathrm{~mL})$ and then concentrated at reduced pressure. The residue was taken up in ether $(10 \mathrm{~mL})$ and extracted with $5 \% \mathrm{NaOH}_{(\mathrm{aq})}(3 \times 5 \mathrm{~mL})$. The basic extracts were combined, cooled in an ice bath, and then acidified with $10 \% \mathrm{HCl}_{(\mathrm{aq})}$. The aqueous phase was extracted $(3 \times 15 \mathrm{~mL})$ with ether/ethyl acetate 1:1. The organic phases were combined, washed with brine, dried over anhydrous $\mathrm{MgSO}_{4}$, filtered, and concentrated. 


\section{General procedure H. Decarboxylation of methyl 4-oxo-2-cyclohexenecarboxylates}

The substrate (1.0 equiv) was dissolved in DMSO $(3.0 \mathrm{~mL})$. Water $(2 \mathrm{~mL})$ and $\mathrm{LiCl}$ (2 equiv) were added. The reaction mixture was heated at $145^{\circ} \mathrm{C}$ on an oil bath for $6 \mathrm{~h}$, and was cooled to room temperature and diluted with ether $(10 \mathrm{~mL})$. The organic layer was washed with water $(6 \mathrm{x}$ $3 \mathrm{~mL}$ ) and brine $(3 \mathrm{~mL})$, dried over anhydrous $\mathrm{MgSO}_{4}$, filtered, and then concentrated. The resulting 2-cyclohexenone was purified via flash chromatography.

\section{General procedure I. Decarboxylation of Hagemann diesters}

Into a round bottom flask was placed EtOH $(4 \mathrm{~mL})$, water $(1 \mathrm{~mL})$, and $\mathrm{KOH}$ ( 7 equiv). The diester (1.0 equiv) was dissolved in $\mathrm{EtOH}(5 \mathrm{~mL})$ and added dropwise to the stirred $\mathrm{KOH}$ solution. The reaction mixture was refluxed under nitrogen for $12 \mathrm{~h}$. After cooling, the solution was diluted with water $(10 \mathrm{~mL})$ and then concentrated using a rotary evaporator to remove the ethanol. The reaction mixture was acidified with $6 \mathrm{M} \mathrm{HCl}$ to $\mathrm{pH} 2$ and refluxed for $2 \mathrm{~h}$. After cooling to room temperature, the reaction mixture was extracted with ether $(3 \mathrm{x} 10 \mathrm{~mL})$. The organic layer was washed with water $(5 \mathrm{~mL})$, and brine $(5 \mathrm{~mL})$. The organic layer was dried over anhydrous $\mathrm{MgSO}_{4}$, filtered, and then concentrated. The product was purified by chromatography on silica gel.

\section{General procedure J. 1,2-Addition of an organolithium reagent to 2-cyclohexenones}

Ether $(5 \mathrm{~mL})$ was added to a round bottom flask. $n$-BuLi $(2.5 \mathrm{M}$ solution in hexanes, $9.05 \mathrm{mmol}$, 1.25 equiv) was added and the solution was cooled to $-78{ }^{\circ} \mathrm{C}$. The substrate $(6.96 \mathrm{mmol}, 1.0$ equiv) dissolved in ether $(5 \mathrm{~mL})$ was added dropwise and the resulting reaction mixture was stirred at room temperature for $4 \mathrm{~h}$. The reaction mixture was poured into cold saturated $\mathrm{NH}_{4} \mathrm{Cl}_{(\mathrm{aq})}(20 \mathrm{~mL})$ and extracted with ether $(3 \times 15 \mathrm{~mL})$. The organic layer was washed with water $(5 \mathrm{~mL})$ and brine $(5 \mathrm{~mL})$. The organic layer was dried over anhydrous $\mathrm{MgSO}_{4}$, filtered, and concentrated.

\section{General procedure K. Dehydration of tertiary alcohols}

The allylic alcohol $(1.14 \mathrm{mmol})$ was dissolved in DCM $(2 \mathrm{~mL})$. The resulting solution was cooled to $0{ }^{\circ} \mathrm{C}$. To the stirred solution was added $p$-TsOH $(0.3 \mathrm{mmol})$. The reaction mixture was warmed to room temperature and stirred overnight. The reaction mixture was diluted with DCM $(10 \mathrm{~mL})$ and washed with saturated $\mathrm{NaHCO}_{3(\mathrm{aq})}$ solution $(2 \times 3 \mathrm{~mL})$. The organic layer was dried over anhydrous $\mathrm{MgSO}_{4}$, filtered, and then concentrated. The resulting diene was isolated via chromatography on silica gel.

\section{General procedure L. Aromatization of dienes using the Horning protocol ${ }^{14 \mathrm{~b}, \mathrm{c}}$}

The diene (251 mmol, 1.0 equiv) was dissolved in ethylene glycol (4 mL). To this solution was added $10 \% \mathrm{Pd} / \mathrm{C}$ (15\% of the weight of the substrate). The resulting solution was refluxed for 4 h. The reaction mixture was cooled to $50{ }^{\circ} \mathrm{C}$, diluted with hot ethyl acetate $(10 \mathrm{~mL})$, and the reaction mixture was filtered to remove the catalyst. The recovered catalyst was washed with hot 
ethyl acetate $(3 \times 10 \mathrm{~mL})$. The organic phases were combined, washed with water $(3 \times 7 \mathrm{~mL})$ and brine $(5 \mathrm{~mL})$. The organic layer was dried over anhydrous $\mathrm{MgSO}_{4}$, filtered, and then concentrated. The resulting arene was purified by flash chromatography on silica gel.

Methyl 2,6-dimethyl-4-oxo-2-cyclohexenecarboxylate (18). The mixture of ethyl acetate (52.75 g, $454 \mathrm{mmol})$ and freshly distilled acetaldehyde $(9.0 \mathrm{~g}, 204 \mathrm{mmol})$ was cooled to $-5{ }^{\circ} \mathrm{C}$. Piperidine (348 mg, $4.08 \mathrm{mmol})$ and ethanol $(1.5 \mathrm{~mL})$ were added, and the mixture was swirled. The flask was stoppered with a cork stopper and refrigerated for $24 \mathrm{~h}$. Additional piperidine (348 $\mathrm{mg}$ ) in ethanol $(1.5 \mathrm{~mL})$ was added, the contents swirled, and refrigerated for an additional $24 \mathrm{~h}$. The same amount of piperidine in ethanol was added, and after a total of $26 \mathrm{~h}$ of refrigeration, the reaction mixture was allowed to stand unstoppered at room temperature for $24 \mathrm{~h}$. A watercooled condenser was added to the reaction flask and the reaction mixture was heated to $100{ }^{\circ} \mathrm{C}$ on a hot water bath. A distillation apparatus replaced the condenser and ethanol and piperidine were distilled off at atmospheric pressure. The distillation of the residue was continued under high vacuum. Product 18 (32.0 g, 86\%), bp $115-120{ }^{\circ} \mathrm{C}(3 \mathrm{~mm} \mathrm{Hg})$, was isolated as an oil and was a mixture of diastereomers of approximately the same $\mathrm{R}_{f}=0.27$ (hexanes/ethyl acetate, 4:1). ${ }^{1} \mathrm{H}$ NMR (300 MHz): $\delta$ 1.06-1.09 (m, $\left.3 \mathrm{H}\right), 1.93-19.5$ (m, $\left.3 \mathrm{H}\right), 2.07-2.16$ (m, $\left.1 \mathrm{H}\right), 2.53-2.61$ (m, $2 \mathrm{H}), 3.02-3.05(\mathrm{~m}, 1 \mathrm{H}), 3.73-3.77$ (m, $3 \mathrm{H})$, 5.96-5.97 (m, 1H).

Methyl 2-methyl-4-oxo-6-phenyl-2-cyclohexenecarboxylate (22). Benzaldehyde (1.06 g, 10.0 $\mathrm{mmol})$ and methyl acetoacetate $(2.32 \mathrm{~g}, 20.0 \mathrm{mmol})$ were mixed in a round bottom flask at room temperature. Piperidine ( $85 \mathrm{mg}, 1 \mathrm{mmol}$ ) was added, and the mixture was stirred for $24 \mathrm{~h}$, during which time a solid mass formed. The solid mass was broken up using a spatula and washed with cold $50 \%$ aqueous ethanol. The solid was then dissolved in dichloromethane $(15 \mathrm{~mL} / \mathrm{g}$ of solid), and piperidine $(425 \mathrm{mg}, 5 \mathrm{mmol}$ ) was added. The reaction mixture was stirred for $4 \mathrm{~d}$. The reaction mixture was washed with water and brine. The organic layer was dried over anhydrous $\mathrm{MgSO}_{4}$, filtered, and then concentrated to yield a crude residue (2.31 g). Chromatographic separation (silica gel, hexanes/ethyl acetate 1:1) yielded 22 as a light yellow oil (1.78 g, 73\%), which was a mixture of diastereomers of approximately the same $\mathrm{R}_{f}=0.55$ (hexanes/ethyl acetate 1:1). ${ }^{1} \mathrm{H}$ NMR (250 MHz): $\delta$ 1.97-1.98 (m, $\left.3 \mathrm{H}\right), 2.55-2.73(\mathrm{~m}, 2 \mathrm{H}), 3.58-3.70(\mathrm{~m}, 5 \mathrm{H})$, 6.05-6.06 (m, $1 \mathrm{H}), 7.18-7.32(\mathrm{~m}, 5 \mathrm{H})$.

Methyl 4-hydroxy-2,6-dimethylbenzoate (19). The reaction followed general procedure B using $18(1.00 \mathrm{~g}, 5.50 \mathrm{mmol})$, $t$-butyl alcohol $(30 \mathrm{~mL})$, and iodine $(2.79 \mathrm{~g}, 11.00 \mathrm{mmol})$. The reaction mixture was refluxed for $3 \mathrm{~d}$. Standard workup furnished a crude residue $(650 \mathrm{mg})$. Chromatographic separation (silica gel, hexanes/ethyl acetate 3:2) gave phenol 19 (598 mg, $60 \%$ ) as an oil, which was homogeneous by TLC analysis, $\mathrm{R}_{f}=0.24$ (hexanes/ethyl acetate 4:1). ${ }^{1} \mathrm{H}$ NMR (300 MHz): $\delta 2.27$ (s, $\left.6 \mathrm{H}\right), 3.89$ (s, $\left.3 \mathrm{H}\right), 5.61$ (bs, $\left.1 \mathrm{H}\right), 6.48$ (s, $\left.2 \mathrm{H}\right) .{ }^{13} \mathrm{C}$ NMR $(75.5$ MHz): $\delta 170.8,156.4,138.0,114.6,113.0,51.9,20.1$. GC-MS: $m / z(\%) 180(40), 149$ (100), 121 (20). IR (film): v 3299,1691, 1606, $1300 \mathrm{~cm}^{-1}$.

Methyl 2,3,6-trimethyl-4-oxo-2-cyclohexenecarboxylate (20). The reaction was set up as in general procedure A using methyl 2,6-dimethyl-4-oxo-2-cyclohexenecarboxylate 18 (6.40 g, $35.16 \mathrm{mmol})$, THF (70 mL), and iodomethane (17.86 g, $70.32 \mathrm{mmol})$. Standard workup gave a 
crude residue ( $4.83 \mathrm{~g}$ ). Column chromatography (silica gel, hexanes/ethyl acetate 4:1) afforded product 20 as an oil (4.43 g, 64\%), which was a mixture of diastereomers of approximately the same $\mathrm{R}_{f}=0.36$ (hexanes/ethyl acetate $\left.4: 1\right) .{ }^{1} \mathrm{H}$ NMR $(300 \mathrm{MHz}): \delta 1.01-1.05(\mathrm{~m}, 3 \mathrm{H}), 1.73-$ 1.79 (m, $3 \mathrm{H}), 1.88-1.91$ (m, 3H), 2.26-2.68 (m, $3 \mathrm{H}), 3.07-3.23$ (m, 1 H), 3.71-3.75 (m, $3 \mathrm{H})$.

Methyl 2,3-dimethyl-4-oxo-6-phenyl-2-cyclohexenecarboxylate (23). The reaction was set up as described in general procedure A using enone 22 (3.65 g, $26.22 \mathrm{mmol})$, THF (35 mL), and iodomethane $(5.58 \mathrm{~g}, 39.33 \mathrm{mmol})$. Standard workup furnished a crude residue $(3.71 \mathrm{~g})$. Chromatographic separation (silica gel, elution with hexanes/ethyl acetate 3:1) yielded 23 as an oil $(2.13 \mathrm{~g}, 55 \%)$, which was a mixture of diastereomers of approximately the same $\mathrm{R}_{f}=0.41$ (hexanes/ethyl acetate 3:1). ${ }^{1} \mathrm{H}$ NMR (300 MHz): $\delta$ 1.85-2.07 (m, $\left.3 \mathrm{H}\right), 2.56-2.80(\mathrm{~m}, 2 \mathrm{H})$, 3.31-3.64 (m, $5 \mathrm{H}), 7.08-7.36$ (m, $5 \mathrm{H})$.

Methyl 4-hydroxy-2,3,6-trimethylbenzoate (21). The reaction was performed as described in general procedure B using 20 (1.23 g, $6.27 \mathrm{mmol}), t$-butyl alcohol $(45 \mathrm{~mL})$, and iodine $(3.18 \mathrm{~g}$, $12.54 \mathrm{mmol}$ ). The reaction mixture was refluxed for $3 \mathrm{~d}$. Standard workup furnished a crude residue (860 mg). Column chromatography (silica gel, DCM/acetone 40:1) yielded phenol 21 as a light yellow oil (799 mg, 65\%), which was homogeneous by TLC analysis, $\mathrm{R}_{f}=0.33$ (hexanes/ethyl acetate 4:1). ${ }^{1} \mathrm{H}$ NMR $(300 \mathrm{MHz}): \delta 2.13(\mathrm{~s}, 3 \mathrm{H}), 2.20(\mathrm{~s}, 3 \mathrm{H}), 2.22(\mathrm{~s}, 3 \mathrm{H})$, 3.89 (s, $3 \mathrm{H}), 4.82(\mathrm{~s}, 1 \mathrm{H}), 6.47(\mathrm{~s}, 1 \mathrm{H}) .{ }^{13} \mathrm{C}$ NMR $(75.5 \mathrm{MHz}): \delta 171.5,154.2,135.2,133.1$, 126.9, 120.3, 114.1, 51.9, 19.4, 17.2, 11.2. GC-MS: m/z (\%) 194 (40), 163 (100), 135 (20), 91 (20). IR (film): v 3323, 2915, $1689 \mathrm{~cm}^{-1}$.

Methyl 5-hydroxy-3,4-dimethylbiphenyl-2-carboxylate (24). The reaction was performed as described in general procedure B using 23 (693 mg, $2.68 \mathrm{mmol}), t$-butyl alcohol $(20 \mathrm{~mL})$, and iodine $(1.36 \mathrm{~g}, 5.36 \mathrm{mmol})$. The reaction mixture was refluxed for $5 \mathrm{~d}$. Standard workup gave a crude residue (402 mg). Chromatographic separation (silica gel, elution with hexanes/ethyl acetate 4:1) yielded phenol $\mathbf{2 4}$ as an oil (232 $\mathrm{mg}, 34 \%$ ), homogeneous by TLC analysis $\mathrm{R}_{f}=0.32$ (hexanes/ethyl acetate 4:1). ${ }^{1} \mathrm{H}$ NMR $(300 \mathrm{MHz}): \delta 2.20(\mathrm{~s}, 3 \mathrm{H}), 2.28(\mathrm{~s}, 3 \mathrm{H}), 3.54(\mathrm{~s}, 3 \mathrm{H})$, $5.33(\mathrm{~s}, 1 \mathrm{H}), 6.61(\mathrm{~s}, 1 \mathrm{H}), 7.26-7.37$ (m, $5 \mathrm{H}) .{ }^{13} \mathrm{C}$ NMR $(75.5 \mathrm{MHz}): \delta 171.1,154.2,140.6$, 138.7, 135.7, 128.2, 128.0, 127.2, 126.3, 122.1, 113.8, 51.9, 17.11, 11.6. GC-MS: $\mathrm{m} / z(\%) 256$ (55), 225 (100), 182 (15). IR (film): 3391, 1698, $1268 \mathrm{~cm}^{-1}$.

Methyl 4-(allyloxy)-2,3,6-trimethylbenzoate (25). The reaction was set up as in the general procedure C using phenol 21 (84 mg, $0.38 \mathrm{mmol}$ ), DMF (1 mL), allyl chloride (40.3 $\mathrm{mg}, 0.53$ $\mathrm{mmol}$ ) and potassium carbonate $(74.5 \mathrm{mg}, 0.76 \mathrm{mmol})$. Standard workup provided a crude residue (91 mg). Chromatographic separation (silica gel, elution with hexanes/ethyl acetate 9:1) yielded ether 25 as an oil ( $80 \mathrm{mg}, 79 \%$ ), homogeneous by TLC analysis, $\mathrm{R}_{f}=0.68$ (hexanes/ethyl acetate 9:1). ${ }^{1} \mathrm{H}$ NMR (250 MHz): $\delta 2.15(\mathrm{~s}, 3 \mathrm{H}), 2.20(\mathrm{~s}, 3 \mathrm{H}), 2.27(\mathrm{~s}, 3 \mathrm{H}), 3.89(\mathrm{~s}, 3 \mathrm{H})$, 4.51-4.53 (m, $2 \mathrm{H})$, 5.25-5.30 (m, $1 \mathrm{H}), 5.38-5.45$ (m, $1 \mathrm{H})$, 5.98-6.12 (m, $1 \mathrm{H}), 6.53$ (s, $1 \mathrm{H})$. ${ }^{13} \mathrm{C}$ NMR $(62.9 \mathrm{MHz}): \delta 171.1,156.8,134.7,133.3,132.9,127.1,123.1,117.0,110.8,68.9$, 51.8, 19.9, 17.2, 11.5. GC-MS: m/z (\%) 234 (100), 203 (85), 161 (90), 133 (75). IR (film): 2914, $1272,1151 \mathrm{~cm}^{-1}$.

Methyl 5-(allyloxy)-3,4-dimethylbiphenyl-2-carboxylate (27). The reaction was set up as in 
the general procedure $\mathrm{C}$ using phenol $24(81 \mathrm{mg}, 0.27 \mathrm{mmol}) \mathrm{DMF}(1 \mathrm{~mL})$, allyl chloride (28.7 $\mathrm{mg}, 0.38 \mathrm{mmol})$, and potassium carbonate $(53 \mathrm{mg}, 0.54 \mathrm{mmol})$. Standard workup furnished a crude residue ( $89 \mathrm{mg}$ ). Chromatographic separation (silica gel, hexanes/ethyl acetate 4:1) yielded ether 27 as a pale oil (75 mg, 80\%), homogeneous by TLC analysis, $\mathrm{R}_{f}=0.72$ (hexanes/ethyl acetate 4:1). ${ }^{1} \mathrm{H}$ NMR (300 MHz): $\delta 2.24(\mathrm{~s}, 3 \mathrm{H}), 2.30(\mathrm{~s}, 3 \mathrm{H}), 3.55$ (s, $\left.3 \mathrm{H}\right), 4.56-4.59$ (m, 2 H), 5.27-5.31 (m, 1 H), 5.40-5.46 (m, 1 H), 6.04-6.11 (m, 1 H), 6.71 (s, 1 H), 7.32-7.41 (m, 5 H). ${ }^{13} \mathrm{C}$ NMR $(75.5 \mathrm{MHz}): \delta 170.9,156.8,141.3,138.4,135.3,133.2,128.2,128.1,127.2,126.5$, 125.0, 117.2, 110.5, 69.0, 51.8, 17.1, 11.8. GC-MS: m/z (\%) 296 (100), 265 (50), 195 (80). IR (film): $v$ 2914, 1723, 1262, $1170 \mathrm{~cm}^{-1}$.

Methyl 3-allyl-4-hydroxy-2,5,6-trimethylbenzoate (26). The reaction was set up as in general procedure D using ether 25 (100 $\mathrm{mg}, 0.43 \mathrm{mmol})$ and $N, N$-diethylaniline $(100 \mathrm{mg})$. Standard workup provided a crude residue $(100 \mathrm{mg})$. Chromatographic separation (silica gel, hexanes/ethyl acetate 4:1) gave phenol 26 as an oil (89 mg, 89\%), homogeneous by TLC analysis, $\mathrm{R}_{f}=0.41$ (hexanes/ethyl acetate 4:1). ${ }^{1} \mathrm{H}$ NMR $(300 \mathrm{MHz}): \delta 2.14(\mathrm{~s}, 3 \mathrm{H}), 2.17(\mathrm{~s}, 3 \mathrm{H}), 2.17(\mathrm{~s}$, $3 \mathrm{H}), 3.40-3.42(\mathrm{~m}, 2 \mathrm{H}), 3.89$ (s, $3 \mathrm{H}), 5.01-5.11(\mathrm{~m}, 2 \mathrm{H}), 5.86-5.97$ (m, $1 \mathrm{H}) .{ }^{13} \mathrm{C}$ NMR $(75.5$ MHz): $\delta 171.8,152.9,135.1,132.2,130.9,128.2,120.9,120.6,116.1,52.0,30.9,17.1,16.6$, 11.7. GC-MS: $m / z$ (\%) 234 (60), 203 (100), 40 (50). IR (film): $v 2923,1710,1196 \mathrm{~cm}^{-1}$.

Methyl 6-allyl-5-hydroxy-3,4-dimethylbiphenyl-2-carboxylate (28). The reaction was set up as in general procedure D using ether $27(50 \mathrm{mg}, 0.16 \mathrm{mmol})$ and $N, N$-diethylaniline (100 mg $0.67 \mathrm{mmol})$. Standard workup furnished a crude residue $(50 \mathrm{mg})$. Chromatographic separation (silica gel, DCM/acetone 90:1) yielded phenol 28 as an oil (41 $\mathrm{mg}, 82 \%$ ), homogeneous by TLC analysis, $\mathrm{R}_{f}=0.42$ (hexanes/ethyl acetate 4:1). ${ }^{1} \mathrm{H}$ NMR $(300 \mathrm{MHz}): \delta 2.22(\mathrm{~s}, 3 \mathrm{H}), 2.26(\mathrm{~s}, 3$ H), 3.16-3.19 (m, 2 H), 3.40 (s, 3 H), 5.07-5.17 (m, 2 H), 5.30 (s, 1 H), 5.82-5.91 (m, 1 H), 7.18-7.35 (m, $5 \mathrm{H}) .{ }^{13} \mathrm{C}$ NMR (75.5 MHz): $\delta$ 170.7, 153.4, 139.1, 137.8, 136.1, 132.8, 129.2, 128.0, 127.8, 127.2, 123.0, 120.1, 116.7, 51.5, 32.3, 17.0, 11.9. GC-MS: $m / z$ (\%) 296 (100), 265 (80), 249 (80). IR (film): $v 3522,1709,1195 \mathrm{~cm}^{-1}$.

3,5-Dimethylcyclohex-2-enone (29). The reaction was set up as in general procedure $\mathrm{H}$ using ester 18 (8.00 g, $4.39 \mathrm{mmol})$, DMSO (50 mL), water $(20 \mathrm{~mL})$, and $\mathrm{LiCl}(0.37 \mathrm{~g}, 8.78 \mathrm{mmol})$. Standard workup produced a crude residue $(5.42 \mathrm{~g})$. Chromatographic separation (silica gel, hexanes/ethyl acetate 4:1) yielded enone 29 as an oil $(3.67 \mathrm{~g}, 67 \%)$, identical to the known compound, 3,5-dimethyl-2-cyclohexen-1-one [1123-09-7]. $\mathrm{R}_{f}=0.22$ (hexanes/ethyl acetate 4:1). ${ }^{1} \mathrm{H}$ NMR (250 MHz): $\delta 1.05$ (d, $\left.J=6 \mathrm{~Hz}, 3 \mathrm{H}\right), 1.95$ (s, $\left.3 \mathrm{H}\right), 2.00-2.45$ (m, $\left.5 \mathrm{H}\right), 5.86$ (s, $1 \mathrm{H}$ ).

3,5-Dimethylphenol (30). The reaction was set up as in general procedure $\mathrm{G}$ using enone 29 (900 mg, $8.18 \mathrm{mmol})$, ethylene glycol $(9.0 \mathrm{~mL})$ and $10 \% \mathrm{Pd} / \mathrm{C}(100 \mathrm{mg})$. Standard workup furnished phenol 30 as an oil (652 mg, 74\%), identical to the known compound, 3,5dimethylphenol [108-68-9]. $\mathrm{R}_{f}=0.43$ (hexanes/ethyl acetate 4:1). ${ }^{1} \mathrm{H}$ NMR $(250 \mathrm{MHz}): \delta 2.27$ (s, $6 \mathrm{H}), 6.48$ (s, $2 \mathrm{H}), 6.59$ (s, $1 \mathrm{H})$.

2,3,5-Trimethylcyclohex-2-enone (31). The reaction was set up as in general procedure $\mathrm{H}$ using 20 (509 mg, $2.10 \mathrm{mmol}$ ), DMSO (3 mL), water (2 mL), and LiCl (176 mg, $0.42 \mathrm{mmol}$ ). Standard workup provided a crude residue $(350 \mathrm{mg})$. Column chromatography (silica gel, hexanes/ethyl 
acetate 4:1) yielded enone $\mathbf{3 1}$ as an oil (257 mg, 72\%), identical to the known compound, 2,3,5dimethyl-2-cyclohexenone [93445-20-6]. $\mathrm{R}_{f}=0.34$ (hexanes/ethyl acetate 4:1). ${ }^{1} \mathrm{H}$ NMR (250 $\mathrm{MHz}): \delta 1.00$ (d, $J=6 \mathrm{~Hz}, 3 \mathrm{H}), 1.74(\mathrm{~s}, 3 \mathrm{H}), 1.90$ (s, 3H), 2.01-2.47 (m, $5 \mathrm{H})$.

2,3,5-Trimethylphenol (32). The reaction was set up as in general procedure $\mathrm{G}$ using enone 31 $(582 \mathrm{mg}, 4.21 \mathrm{mmol})$, ethylene glycol $(6 \mathrm{~mL})$, and $10 \% \mathrm{Pd} / \mathrm{C}(60 \mathrm{mg})$. Following basic extraction, the solvent was removed at reduced pressure to yield phenol $\mathbf{3 2}$ as an oil (402 $\mathrm{mg}$, $70 \%$ ), identical to the known compound, 2,3,5-trimethylphenol [697-82-5]. $\mathrm{R}_{f}=0.41$ (hexanes/ethyl acetate 4:1). ${ }^{1} \mathrm{H}$ NMR $(250 \mathrm{MHz}): \delta 2.15(\mathrm{~s}, 3 \mathrm{H}), 2.26(\mathrm{~s}, 6 \mathrm{H}), 4.60(\mathrm{~s}, 1 \mathrm{H})$, 6.48 (s, $1 \mathrm{H}), 6.62$ (s, $1 \mathrm{H})$.

Methyl 2,6-dimethyl-4-(trifluoromethylsulfonyloxy)benzoate (33). The reaction was set up as in general procedure E using phenol $19(352 \mathrm{mg}, 1.13 \mathrm{mmol})$, pyridine $(1.5 \mathrm{~mL})$, and triflic anhydride (261 mg, $1.24 \mathrm{mmol}$ ). After standard workup, the solvent was removed at reduced pressure to yield a crude residue $(514 \mathrm{mg}$ ). Chromatographic separation (silica gel, hexanes/ethyl acetate 9:1) yielded triflate 33 as an oil (400 mg, 66\%), homogeneous by TLC analysis, $\mathrm{R}_{f}=0.56$ (hexanes/ethyl acetate 4:1). ${ }^{1} \mathrm{H}$ NMR $(250 \mathrm{MHz}): \delta 2.34(\mathrm{~s}, 6 \mathrm{H}), 3.93(\mathrm{~s}, 3 \mathrm{H}), 6.96(\mathrm{~s}, 2 \mathrm{H}) .{ }^{13} \mathrm{C}$ NMR $(62.9 \mathrm{MHz}): \delta 169.0,149.4,138.2,134.1,121.2,120.1,52.3,19.8$. GC-MS: $\mathrm{m} / z(\%) 312$ (50), 281 (100), 91 (70), 69 (99). IR (film): v 1732, 1421, 1210, $1140 \mathrm{~cm}^{-1}$.

Methyl 2,6-dimethyl-4-octylbenzoate (34). The reaction was set up as in general procedure $\mathrm{F}$ using 9-BBN (0.5 M solution in THF, $6.71 \mathrm{mmol}), 1$-octene $(751 \mathrm{mg}, 6.71 \mathrm{mmol})$, dioxane (3 $\mathrm{mL}), \mathrm{K}_{3} \mathrm{PO}_{4}$ (193 mg, $\left.0.91 \mathrm{mmol}\right), \mathrm{Pd}\left(\mathrm{PPh}_{3}\right)_{4}(17 \mathrm{mg}, 0.015 \mathrm{mmol})$, and triflate 33 (191 mg 0.61 $\mathrm{mmol})$. Standard workup gave a crude residue $(237 \mathrm{mg})$. Chromatographic separation (silica gel, hexanes/ethyl acetate 9:1) yielded ester 34 as an oil (96 mg, 57\%), homogeneous by TLC analysis, $\mathrm{R}_{f}=0.40$ (hexanes/ethyl acetate 9:1). ${ }^{1} \mathrm{H} \mathrm{NMR}(250 \mathrm{MHz}): \delta 0.88(\mathrm{t}, J=7 \mathrm{~Hz}, 3 \mathrm{H})$, 1.22-1.38 (m, $10 \mathrm{H}), 1.50-1.61(\mathrm{~m}, 2 \mathrm{H}), 2.29$ (s, $6 \mathrm{H}), 2.52$ (t, $J=8 \mathrm{~Hz}, 2 \mathrm{H}), 3.89$ (s, $3 \mathrm{H}), 6.84$ (s, $2 \mathrm{H}) .{ }^{13} \mathrm{C}$ NMR $(62.9 \mathrm{MHz}): \delta 170.7,144.4,135.1,131.0,127.7,51.7,35.6,31.9,31.3,29.4$, 29.3, 29.2, 22.6, 19.8, 14.1. GC-MS: $m / z$ (\%) 276 (23), 245 (22), 178 (60), 119 (100). IR (film): $v 2923,1728,1436,1267 \mathrm{~cm}^{-1}$.

3,5-Dimethylphenyl trifluoromethanesulfonate (35). The reaction was set up as in general procedure E using 3,5-dimethylphenol $30(1.00 \mathrm{~g}, 3.94 \mathrm{mmol})$, pyridine $(5.0 \mathrm{~mL})$, and triflic anhydride (910 mg, $4.33 \mathrm{mmol})$. Standard workup gave a crude residue $(2.03 \mathrm{~g})$. Chromatographic separation (silica gel, hexanes/ethyl acetate 9:1) yielded 35 as an oil (1.78 g, $86 \%$ ), homogeneous by TLC analysis, $\mathrm{R}_{f}=0.60$ (hexanes/ethyl acetate 4:1). ${ }^{1} \mathrm{H}$ NMR (300 MHz): $\delta 2.35$ (s, $6 \mathrm{H}) .6 .89$ (s, $2 \mathrm{H}), 7.01$ (s, $1 \mathrm{H}) .{ }^{13} \mathrm{C}$ NMR $(62.9 \mathrm{MHz}): \delta$ 149.5, 140.4, 130.0, 121.3, 118.7, 21.2. GC-MS: m/z (\%) 254 (42), 175 (20), 121 (100), 77 (54). IR (film): $v$ 1620, $1587,1423,1211 \mathrm{~cm}^{-1}$.

1,3-Dimethyl-5-octylbenzene (36). The reaction was set up as in general procedure $\mathrm{F}$ using 9BBN (430 $\mu \mathrm{L}, 0.5 \mathrm{M}$ solution in THF, $2.15 \mathrm{mmol})$, 1-octene (240 mg, $2.15 \mathrm{mmol})$, dioxane (8 $\mathrm{mL}$ ), $\mathrm{K}_{3} \mathrm{PO}_{4}$ (623 mg, $\left.2.94 \mathrm{mmol}\right), \mathrm{Pd}\left(\mathrm{PPh}_{3}\right)_{4}(57 \mathrm{mg}, 0.05 \mathrm{mmol})$, and 35 (500 mg, $\left.1.96 \mathrm{mmol}\right)$. Standard workup provided a crude residue (1.12 g). Chromatographic separation (silica gel, hexanes/ethyl acetate 19:1) yielded arene $\mathbf{3 6}$ as an oil (351 $\mathrm{mg}, \mathbf{8 2 \%}$ ), homogeneous by TLC 
analysis, $\mathrm{R}_{f}=0.87$ (hexanes/ethyl acetate 9:1). ${ }^{1} \mathrm{H}$ NMR $(300 \mathrm{MHz}): \delta 0.92(\mathrm{t}, J=7 \mathrm{~Hz}, 3 \mathrm{H})$, 1.25-1.34 (m, $10 \mathrm{H}), 1.60-1.65$ (m, $2 \mathrm{H}), 2.32$ (s, $6 \mathrm{H}), 2.53-3.58$ (t, $2 \mathrm{H}, J=8 \mathrm{~Hz}), 6.84$ (s, 3 H). ${ }^{13} \mathrm{C}$ NMR $(75.5 \mathrm{MHz}): \delta 142.9,137.6,127.2,126.2,35.9,31.9,31.7,29.5,29.3,22.7,21.3$, 14.1. GC-MS: $m / z$ (\%) 218 (16), 120 (100), 105 (20). IR (film): $v 2923,1606,1460 \mathrm{~cm}^{-1}$.

1-Butyl-3,5-dimethylcyclohex-2-enol (38). The reaction was set up as in general procedure $\mathbf{J}$ using enone $29(1.35 \mathrm{~g}, 12.05 \mathrm{mmol})$, ether $(14 \mathrm{~mL})$, and $n$-BuLi $(6.0 \mathrm{~mL}, 2.5 \mathrm{M}$ solution in hexanes, $15.06 \mathrm{mmol})$. Standard workup provided a crude residue $(1.90 \mathrm{~g})$. Chromatographic separation (silica gel, hexanes/ethyl acetate 4:1) yielded alcohol $\mathbf{3 8}$ as an oil (1.51 g, 76\%), homogeneous by TLC analysis, $\mathrm{R}_{f}=0.40$ (hexanes/ethyl acetate $4: 1$ ). This compound was too unstable to be characterized further.

1-Butyl-2,3,5-trimethylcyclohex-2-enol (41). The reaction was set up as in general procedure J using enone 31 (962 mg, $7.75 \mathrm{mmol})$, ether $(10 \mathrm{~mL})$, and $n$-BuLi (3.87 mL, $2.5 \mathrm{M}$ solution in hexanes, $9.68 \mathrm{mmol})$. Standard workup gave a crude residue $(1.33 \mathrm{~g})$. Chromatographic separation (silica gel, hexanes/ethyl acetate 6:1) yielded alcohol $\mathbf{4 1}$ as an oil (1.05 g, 76\%), homogeneous by TLC analysis, $\mathrm{R}_{f}=0.34$ (hexanes/ethyl acetate 6:1). This compound was too unstable to be characterized further.

(E,Z)-3-Butylidene-1,5-dimethylcyclohex-1-ene (39). The reaction was prepared as described in general procedure K using alcohol 38 (1.42 g, $7.89 \mathrm{mmol})$, DCM (14 mL), and p-TsOH (100 $\mathrm{mg}$ ). After standard workup, the solvent was removed at reduced pressure to yield a crude residue $(1.21 \mathrm{~g})$. Chromatographic separation (silica gel, hexanes) yielded diene 39 as an oil (1.15 g, 90\%), a mixture of $E$ and $Z$ isomers with approximately the same $\mathrm{R}_{f}=0.65$ (hexanes). ${ }^{1} \mathrm{H}$ NMR (250 MHz): $\delta$ 0.86-1.00 (m, $\left.6 \mathrm{H}\right), 1.27-1.42$ (m, $\left.4 \mathrm{H}\right), 1.60-1.81$ (m, $\left.5 \mathrm{H}\right), 2.00-2.09$ (m, $2 \mathrm{H}), 2.15-2.45$ (m, $1 \mathrm{H}), 4.97-5.20$ (m, $1 \mathrm{H})$, 5.81-6.15 (m, $1 \mathrm{H})$.

(E,Z)-3-Butylidene-1,2,5-trimethylcyclohex-1-ene (42). The reaction followed general procedure $\mathrm{K}$ using alcohol 41 (1.05 g, $5.83 \mathrm{mmol})$, DCM (14 mL), and p-TsOH (80 mg). Standard workup yielded a crude residue $(914 \mathrm{mg})$. Chromatographic separation (silica gel, hexanes) yielded diene $\mathbf{4 2}$ as an oil (895 mg, 90\%), homogeneous by TLC analysis, $\mathrm{R}_{f}=0.62$ (hexanes). ${ }^{1} \mathrm{H}$ NMR (250 MHz): $\delta$ 0.86-0.98 (m, $\left.6 \mathrm{H}\right), 1.27-1.46$ (m, $\left.4 \mathrm{H}\right), 1.67-1.81$ (m, $\left.8 \mathrm{H}\right)$, 2.00-2.12 (m, $2 \mathrm{H}), 2.50-2.57(\mathrm{~m}, 1 \mathrm{H}), 3.35-3.39(\mathrm{~m}, 1 \mathrm{H}) .{ }^{13} \mathrm{C} \mathrm{NMR}(62.9 \mathrm{MHz}): \delta 136.9$, $130.5,126.3,121.7,41.5,34.3,30.0,28.9,23.1,21.7,20.7,14.0,13.9$. GC-MS: $m / z(\%) 178$ (45), 149 (100), 121 (38), 107 (67). IR (film): $v$ 2952, 1451, $1376 \mathrm{~cm}^{-1}$.

1-Butyl-3,5-dimethylbenzene (40). The reaction was set up as in general procedure $\mathrm{L}$ using diene 39 (412 mg, $2.54 \mathrm{mmol}$ ), ethylene glycol $(4.0 \mathrm{~mL})$, and 10\% $\mathrm{Pd} / \mathrm{C}$ catalyst $(60 \mathrm{mg})$. Standard workup furnished a crude residue $(389 \mathrm{mg}$ ). Chromatographic separation (silica gel, hexanes) yielded arene 40 as an oil (351 mg, 86\%), homogeneous by TLC analysis, $\mathrm{R}_{f}=0.54$ (hexanes). ${ }^{1} \mathrm{H}$ NMR (300 MHz): $\delta 0.93-0.98(\mathrm{t}, J=7 \mathrm{~Hz}, 3 \mathrm{H}), 1.30-1.42$ (m, $\left.2 \mathrm{H}\right), 1.55-1.63$ $(\mathrm{m}, 2 \mathrm{H}), 2.32(\mathrm{~s}, 6 \mathrm{H}), 2.53-2.58(\mathrm{t}, J=7 \mathrm{~Hz}, 3 \mathrm{H}), 6.83(\mathrm{~s}, 3 \mathrm{H}) .{ }^{13} \mathrm{C} \mathrm{NMR}(75.5 \mathrm{MHz}): \delta$ 142.8, 137.6, 127.2, 126.2, 35.5, 33.8, 22.5, 21.3, 14.0. GC-MS: $m / z$ (\%) 162 (35), 120 (100), 105 (40). IR (film): $v$ 2924, 1602, $1461 \mathrm{~cm}^{-1}$.

1-Butyl-2,3,5-trimethylbenzene (43). The reaction was set up as in general procedure L using 
diene 42 (414 mg, $2.32 \mathrm{mmol})$. ethylene glycol $(4.0 \mathrm{~mL})$, and 10\% Pd/C catalyst $(50 \mathrm{mg})$. After standard workup a crude residue $(375 \mathrm{mg}$ ) was obtained. Chromatographic separation (silica gel, hexanes) yielded arene 43 as an oil (350 mg, 86\%), homogeneous by TLC analysis, $\mathrm{R}_{f}=0.46$ (hexanes). ${ }^{1} \mathrm{H}$ NMR (300 MHz): $\delta 1.01(\mathrm{t}, J=7 \mathrm{~Hz}, 3 \mathrm{H}), 1.42-1.61(\mathrm{~m}, 4 \mathrm{H}), 2.21(\mathrm{~s}, 3 \mathrm{H}), 2.30$ $(\mathrm{s}, 3 \mathrm{H}), 2.32(\mathrm{~s}, 3 \mathrm{H}), 2.61-2.66(\mathrm{t}, J=8 \mathrm{~Hz}, 2 \mathrm{H}), 6.88(\mathrm{~s}, 2 \mathrm{H}) .{ }^{13} \mathrm{C} \mathrm{NMR}(75.5 \mathrm{MHz}): \delta 140.9$, 136.6, 134.5, 131.2, 128.3, 127.6, 33.8, 33.0, 22.9, 20.8, 20.6, 14.5, 14.0, 10.7. GC-MS: m/z (\%) 176 (28), 133 (100), 119 (29). IR (film): v 2932, 1460, 1376, $849 \mathrm{~cm}^{-1}$.

1,5-Dimethyl-3-methylene-1-cyclohexene (44) and 1,3,5-trimethylcyclohexa-1,3-diene (45). Methyltriphenylphosphonium bromide $(4.75 \mathrm{~g}, 13.3 \mathrm{mmol})$ was suspended in ether $(60 \mathrm{~mL})$. The mixture was cooled to $0{ }^{\circ} \mathrm{C}$. $n$-BuLi $(1.87 \mathrm{M}$ solution in hexanes, $12.09 \mathrm{mmol})$ was added dropwise. The resulting solution was stirred at room temperature for $3 \mathrm{~h}$. A solution of enone 29 (500 mg, $4.03 \mathrm{mmol})$ in ether $(40 \mathrm{~mL})$ was added. The reaction mixture was allowed to stir for $12 \mathrm{~h}$. The ether was distilled off while simultaneously adding THF until the reaction solvent was mostly THF. The reaction mixture was refluxed for $6 \mathrm{~h}$. After cooling to room temperature, the solution was diluted with water $(80 \mathrm{~mL})$ and extracted with ether $(3 \times 100 \mathrm{~mL})$. The organic layer was washed with water $(2 \times 70 \mathrm{~mL}), 5 \% \mathrm{HCl}_{(\mathrm{aq})}(50 \mathrm{~mL})$, water $(50 \mathrm{~mL})$, and brine $(40$ $\mathrm{mL}$ ). The organic layer was dried over anhydrous $\mathrm{MgSO}_{4}$, filtered, and then concentrated to yield a crude residue $(350 \mathrm{mg}$ ). Chromatographic separation (silica gel, hexanes) yielded a mixture (237 mg, 48\%) of 3-methylene-1-cyclohexene 44 and cyclohexa-1,3-diene 45, which was aromatized without characterization.

Mesitylene. The mixture of 3-methylene-1-cyclohexene 44 and cyclohexa-1,3-diene 45 (127 mg, $1.04 \mathrm{mmol})$ was mixed with ethylene glycol $(1 \mathrm{~mL})$ and placed in a thick-walled glass tube equipped with a Teflon screw cap (Ace Glass). To this mixture was added 10\% Pd/C catalyst (15 $\mathrm{mg}$ ). The mixture was placed under nitrogen and the tube was sealed. The reaction mixture was heated at $190{ }^{\circ} \mathrm{C}$ for $4 \mathrm{~h}$. After cooling to $50{ }^{\circ} \mathrm{C}$, the reaction mixture was filtered to remove the catalyst, which was washed with hot ethyl acetate $(3 \times 3 \mathrm{~mL})$. The organic phases were combined, washed with water $(3 \times 1.5 \mathrm{~mL})$, and brine $(1 \mathrm{~mL})$. The organic phase was dried over anhydrous $\mathrm{MgSO}_{4}$, filtered, and then concentrated to furnish a crude oily residue (117 $\mathrm{mg}$ ). Column chromatography (silica gel, hexanes) yielded mesitylene [108-67-8] (95 mg, 76\%), $\mathrm{R}_{f}=$ 0.52 (hexanes). ${ }^{1} \mathrm{H}$ NMR (250 MHz): $\delta 2.30$ (s $\left.9 \mathrm{H}\right), 6.83$ (s, 3H).

Dimethyl 4-hydroxy-2,4-dimethyl-6-oxocyclohexane-1,3-dicarboxylate (46). Methyl acetoacetate $(160.00 \mathrm{~g}, 1.37 \mathrm{~mol})$ and freshly distilled acetaldehyde $(27.62 \mathrm{~g}, 626 \mathrm{mmol})$ were mixed together and cooled to $-5{ }^{\circ} \mathrm{C}$. Piperidine $(1.03 \mathrm{~g}, 12 \mathrm{mmol})$ in ethanol $(2 \mathrm{~mL})$ was added and and the mixture was swirled. The reaction mixture was stoppered with a cork stopper and placed in a refrigerator for $24 \mathrm{~h}$. Additional piperidine $(1.03 \mathrm{~g})$ in ethanol was added, swirled, and refrigerated for $24 \mathrm{~h}$. The same amount of piperidine in ethanol was added, and after a total of $36 \mathrm{~h}$ of refrigeration, the reaction mixture was allowed to stand unstoppered at room temperature for $24 \mathrm{~h}$. The solid mass that formed was collected with a Buchner funnel and washed with cold ethanol $(20 \mathrm{~mL})$. The residual solvent was removed at reduced pressure to yield 46 as a white solid (72.32 $\mathrm{g}, 45 \%$ ), homogeneous by TLC analysis, $\mathrm{R}_{f}=0.31$ 
(hexanes:ethyl acetate, 1:1). ${ }^{1} \mathrm{H}$ NMR $(250 \mathrm{MHz}): \delta 0.97(\mathrm{~d}, J=6 \mathrm{~Hz}, 3 \mathrm{H}), 1.25(\mathrm{~s}, 3 \mathrm{H}), 2.35$ $(\mathrm{d}, J=14 \mathrm{~Hz}, 1 \mathrm{H}), 2.54-2.60(\mathrm{~m}, 2 \mathrm{H}), 2.80-2.92(\mathrm{~m}, 1 \mathrm{H}), 3.06(\mathrm{~d}, J=12 \mathrm{~Hz}, 1 \mathrm{H}), 3.75(\mathrm{~s}, 3$ $\mathrm{H}), 3.78(\mathrm{~s}, 3 \mathrm{H}) .{ }^{13} \mathrm{C}$ NMR $(62.9 \mathrm{MHz}): \delta 201.7,175.0,169.1,72.7,63.2,56.9,52.4,52.1,33.9$, 28.4, 18.6. GC-MS: $m / z$ (\%) 140 (15), 112 (37), 69 (46), 40 (100). IR (film): $v$ 3487, 1742, 1709, $1357 \mathrm{~cm}^{-1}$.

Dimethyl 2,4-dimethyl-6-oxocyclohex-4-ene-1,3-dicarboxylate (47). Tertiary alcohol 46 $(64.50 \mathrm{~g}, 0.250 \mathrm{~mol})$ was dissolved in DCM $(250 \mathrm{~mL})$. To this solution was added $p$-TsOH $(61.70 \mathrm{~g}, 0.324 \mathrm{~mol})$. The reaction mixture was stirred at room temperature for $4 \mathrm{~d}$. The reaction mixture was diluted with DCM $(300 \mathrm{~mL})$ and washed with saturated $\mathrm{NaHCO}_{3(\mathrm{aq})}(3 \mathrm{x} 50 \mathrm{~mL})$. The organic layer was dried over anhydrous $\mathrm{MgSO}_{4}$, filtered and then concentrated to yield a crude residue $(59.36 \mathrm{~g})$. Chromatographic separation (silica gel, hexanes/ethyl acetate 2:1) yielded 47 as a white solid $(50.55 \mathrm{~g}, 84 \%)$, a mixture of diastereomers of approximately the same $\mathrm{R}_{f}=0.26$ (hexanes/ethyl acetate 4:1). ${ }^{1} \mathrm{H}$ NMR $(250 \mathrm{MHz}): \delta 0.98-1.26(\mathrm{~m}, 3 \mathrm{H}), 1.91-2.01(\mathrm{~m}$, $3 \mathrm{H}), 2.50-3.50$ (m, $3 \mathrm{H}), 3.63-3.76(\mathrm{~m}, 6 \mathrm{H}), 5.85-5.98(\mathrm{~m}, 1 \mathrm{H})$.

Dimethyl 1,2,4-trimethyl-6-oxocyclohex-4-ene-1,3-dicarboxylate (48). The reaction followed general procedure A using diester 47 (25.1 g, $0.104 \mathrm{~mol}$ ), THF (a total of $300 \mathrm{~mL}$ ), and iodomethane $(22.15 \mathrm{~g}, 0.156 \mathrm{~mol})$. Standard workup gave a crude residue $(24.94 \mathrm{~g})$. Column chromatography (silica gel, hexanes/ethyl acetate $4: 1$ ) yielded 48 as an oil (20.1 g, 76\%), homogeneous by TLC analysis, $\mathrm{R}_{f}=0.32$ (hexanes/ethyl acetate 4:1). ${ }^{1} \mathrm{H}$ NMR $(300 \mathrm{MHz}): \delta$ 1.04-1.06 (m, $3 \mathrm{H}), 1.41(\mathrm{~s}, 3 \mathrm{H}), 1.89$ (s, $3 \mathrm{H}), 2.32-2.38(\mathrm{~m}, 1 \mathrm{H}), 3.49-3.52(\mathrm{~m}, 1 \mathrm{H}), 3.63$ (s, $3 \mathrm{H}), 3.76(\mathrm{~s}, 3 \mathrm{H}), 5.98(\mathrm{~s}, 1 \mathrm{H}) .{ }^{13} \mathrm{C} \mathrm{NMR}(75.5 \mathrm{MHz}): \delta 194.8,173.0,170.7,156.3,126.9$, 61.2, 55.9, 53.0, 52.2, 40.7, 21.8, 18.6, 14.6. GC-MS: m/z (\%) 223 (6), 163 (8), 140 (58), 112 (100). IR (film): v 2951, 1733, 1667, $1249 \mathrm{~cm}^{-1}$.

3,5,6-Trimethylcyclohex-2-enone (49). The reaction applied general procedure I using diester 48 (692 mg, $2.72 \mathrm{mmol})$, ethanol (9 mL), water (1 mL), and $\mathrm{KOH}$ (647 mg, $19.0 \mathrm{mmol})$. Standard workup furnished a crude residue $(340 \mathrm{mg})$. Chromatographic separation (silica gel, hexanes/ethyl acetate 9:1) gave an oil 49 (282 $\mathrm{mg}, 75 \%)$, a mixture of diastereomers of approximately the same $\mathrm{R}_{f}=0.42$ (hexanes/ethyl acetate $\left.4: 1\right) .{ }^{1} \mathrm{H}$ NMR $(250 \mathrm{MHz}) \delta 0.91-1.26$ (m, $6 \mathrm{H}), 1.91$ (s, $3 \mathrm{H}), 1.92-2.39$ (m, $4 \mathrm{H}), 5.78-5.83$ (m, $1 \mathrm{H})$.

2,3,5-Trimethylphenol (32). The reaction was carried out as in general procedure $\mathrm{G}$ using enone 49 (175 mg, $1.26 \mathrm{mmol})$, ethylene glycol (2 mL), and 10\% Pd/C (200 mg). Following basic extraction, the solvent was removed at reduced pressure to yield phenol $\mathbf{3 2}$ as an oil (99 $\mathrm{mg}$, $58 \%$ ), identical to the known compound, 2,3,5-trimethylphenol [697-82-5]. $\mathrm{R}_{f}=0.41$ (hexanes/ethyl acetate 4:1). ${ }^{1} \mathrm{H}$ NMR $(250 \mathrm{MHz}): \delta 2.15(\mathrm{~s}, 3 \mathrm{H}), 2.26(\mathrm{~s}, 6 \mathrm{H}), 4.60(\mathrm{~s}, 1 \mathrm{H})$, 6.48 (s, $1 \mathrm{H}), 6.62$ (s, $1 \mathrm{H})$.

Dimethyl 1,2,4,5-tetramethyl-6-oxocyclohex-4-ene-1,3-dicarboxylate (50). The reaction applied general procedure A using diester 48 (16.72 g, $62.38 \mathrm{mmol})$, THF (175 mL), and iodomethane (13.28 g, $93.57 \mathrm{~mol})$. Standard workup provided a crude residue (17.18 g). Chromatographic separation (silica gel, hexanes/ ethyl acetate 4:1) gave diester $\mathbf{5 0}$ as an oil $\left(14.22,80 \%\right.$ ), a mixture of diastereomers of approximately the same $\mathrm{R}_{f}=0.38$ (hexanes/ethyl 
acetate 4:1). ${ }^{1} \mathrm{H}$ NMR (300 MHz): $\delta$ 0.89-1.06 (m, $\left.3 \mathrm{H}\right), 1.38-1.42(\mathrm{~m}, 3 \mathrm{H}), 1.77-1.90(\mathrm{~m}, 6 \mathrm{H})$, 2.12-2.28 (m, $1 \mathrm{H}), 3.46-3.50(\mathrm{~m}, 1 \mathrm{H}), 3.62-3.75(\mathrm{~m}, 6 \mathrm{H})$.

2,3,5,6-Tetramethylcyclohex-2-enone (51). The reaction followed general procedure I using diester 50 (8.25 g, $30.78 \mathrm{mmol})$, ethanol $(125 \mathrm{~mL})$, water $(15 \mathrm{~mL})$, and $\mathrm{KOH}(7.33 \mathrm{~g}, 215.4$ $\mathrm{mmol}$ ). Standard workup provided a crude residue (4.32 g). Chromatographic separation (silica gel, hexanes/ethyl acetate 9:1) gave enone $\mathbf{5 1}$ as a light yellow oil (2.68 g, 57\%), a mixture of diastereomers of approximately the same $\mathrm{R}_{f}=0.53$ (hexanes/ethyl acetate 4:1). ${ }^{1} \mathrm{H}$ NMR (250 MHz): $\delta$ 0.89-1.14 (m, $6 \mathrm{H}), 1.74$ (s, $3 \mathrm{H}), 1.89$ (s, $3 \mathrm{H}), 1.89-2.46$ (m, $4 \mathrm{H})$.

2,3,5,6-Tetramethylcyclohex-2-enol (52). Diisobutylaluminum hydride (1.0 $\mathrm{M}$ in toluene, 4.53 $\mathrm{mmol}$ ) was added to a round bottom flask and cooled to $-78{ }^{\circ} \mathrm{C}$. Enone 51 (276 $\left.\mathrm{mg}, 1.81 \mathrm{mmol}\right)$ dissolved in ether $(2 \mathrm{~mL})$ was added dropwise. After stirring at $-78{ }^{\circ} \mathrm{C}$ for $30 \mathrm{~min}$, the reaction mixture was poured into ice-cold saturated $\mathrm{NH}_{4} \mathrm{Cl}_{(\mathrm{aq})}$ solution $(5 \mathrm{~mL})$. The aqueous layer was extracted with ether $(3 \times 10 \mathrm{~mL})$. The organic extracts were combined, washed with $5 \% \mathrm{HCl}_{(\mathrm{aq})}$ (3 $x 7 \mathrm{~mL})$, water $(7 \mathrm{~mL})$, and brine $(7 \mathrm{~mL})$. The organic phase was dried over anhydrous $\mathrm{MgSO}_{4}$, filtered, and then concentrated to yield a crude residue (278 $\mathrm{mg}$ ). Chromatographic separation (silica gel, hexanes/ethyl acetate 4:1) gave alcohol $52(227 \mathrm{mg}, 81 \%)$ as a yellow oil, homogeneous based on TLC analysis, $\mathrm{R}_{f}=0.40$ (hexanes/ethyl acetate $4: 1$ ). This compound was too unstable to be characterized.

\section{2,3,5,6-Tetramethylcyclohexa-1,3-diene (53) and 1,2,4,5-tetramethylcyclohexa-1,3-diene} (54). The reaction was carried out as in general procedure $\mathrm{K}$ using alcohol 52 (100 mg, 0.65 $\mathrm{mmol})$, DCM (1 mL), and $p$-TsOH (10 mg). Standard workup provided a crude residue (90 $\mathrm{mg}$ ). Chromatographic separation (silica gel, hexanes) gave a mixture of cyclohexa-1,3-dienes $\mathbf{5 3}$ and 54 (72 mg, 82\%), $\mathrm{R}_{f}=0.76$ (hexanes).

1,2,4,5-Tetramethylbenzene (55). The reaction was carried out as in general procedure $\mathrm{L}$ using the mixture of cyclohexa-1,3-dienes 53 and 54 (55 mg), ethylene glycol (1.0 mL), and 10\% Pd/C (40 mg). Standard workup provided 55 as an oil (35 $\mathrm{mg}, 61 \%$ ), identical to the known compound, 1,2,4,5-tetramethylbenzene [95-93-2]. $\mathrm{R}_{f}=0.47$ (hexanes). ${ }^{1} \mathrm{H}$ NMR $(250 \mathrm{MHz}): \delta$ $2.21(\mathrm{~s}, 12 \mathrm{H}), 6.92(\mathrm{~s}, 2 \mathrm{H})$.

1-Butyl-2,3,5,6-tetramethylcyclohex-2-enol (56). The reaction followed general procedure $\mathbf{J}$ using enone $51(252 \mathrm{mg}, 1.65 \mathrm{mmol})$, ether $(2 \mathrm{~mL})$ and $n$-BuLi $(825 \mu \mathrm{L}, 2.5 \mathrm{M}$ solution in hexanes, $2.06 \mathrm{mmol}$ ). Standard workup provided alcohol 56 as an oil (233 mg), homogeneous by TLC analysis, $\mathrm{R}_{f}=0.32$ (hexanes/ethyl acetate 9:1). This compound was too unstable to be characterized.

3-Butylidene-1,2,4,5-tetramethylcyclohex-1-ene (57). The reaction was prepared as in general procedure K using cyclohexenol 56 (233 mg, $1.12 \mathrm{mmol})$, DCM (3 mL), and $p$-TsOH (15 mg). Standard workup provided a crude residue $(178 \mathrm{mg}$ ). Chromatographic separation (silica gel, hexanes) yielded cyclohexene 57 (148 mg; 77\% from 51), homogeneous by TLC analysis, $\mathrm{R}_{f}=$ 0.73 (hexanes).

3-Butyl-1,2,4,5-tetramethylbenzene (58). The reaction was carried out as in general procedure L using 57 (45 mg, $0.23 \mathrm{mmol})$, ethylene glycol $(0.5 \mathrm{~mL})$, and 10\% Pd/C (40 mg). Standard 
workup provided a crude residue $(43 \mathrm{mg})$. Chromatographic separation (silica gel, hexanes) yielded 58 as an oil (37 mg, 84\%), homogeneous by TLC analysis, $\mathrm{R}_{f}=0.58$ (hexanes). ${ }^{1} \mathrm{H} \mathrm{NMR}$ (250 MHz): $\delta 0.97-1.03(\mathrm{~m}, 3 \mathrm{H}), 1.44-1.49(\mathrm{~m}, 4 \mathrm{H}), 2.22$ (s, $3 \mathrm{H}), 2.25$ (s, $3 \mathrm{H}), 2.64-2.70$ (m, $2 \mathrm{H}), 6.86(\mathrm{~s}, 1 \mathrm{H}) .{ }^{13} \mathrm{C}$ NMR $(62.9 \mathrm{MHz}): \delta 139.4,133.6,131.9,129.2,31.8,30.0,23.3,20.6$, 15.4, 14.0. GC-MS: m/z (\%) 190 (21), 147 (100), 133 (13); IR (film). $\sim 2955,2923,1456 \mathrm{~cm}^{-1}$.

\section{Acknowledgements}

The principal author thanks Dr. Rajendra Kumar Singh, then a doctoral candidate, for introducing him to the fascinating chemistry of Hagemann's ester as part of his undergraduate research experience at Carnegie-Mellon University (Fall and Spring Semesters 1973/1974).

\section{References}

${ }^{\S}$ Taken in part from the MS thesis of Scott Allen, University of Georgia, 1997.

'Professor James M. Cook is not related to the legendary Captain James Cook of His Majesty's Royal Navy, who discovered Hawaii in 1778. But on July 27, 2006 Professor James M. Cook captained the Academic All-Stars to a 5-2 victory over the Industrial All-Stars in a softball game held at the $55^{\text {th }}$ Gordon Research Conference on Natural Products.

1. Scott, A. I.; Devon, T. K. Handbook of Naturally Occurring Compounds, Academic Press: New York, 1972.

2. Tetrasubstituted phenols: (a) Ramachary, D. B.; Narayana, V. V.; Prasad, M. S.; Ramakumar, K. Org. Biomol. Chem. 2009, 7, 3372. (b) Covarrubias-Zuniga, A.; RiosBarrios, E. J. Org. Chem. 1997, 62, 5688. (c) Bi, X.; Dong, D.; Liu, Q.; Pan, W.; Zhao, L.; Li, B. J. Am. Chem. Soc. 2005, 127, 4578. Pentasubstituted arenes: (d) Paulsen, H.; Antons, S.; Brandes, A.; Logers, M.; Müller, S. N.; Naab, P.; Schmeck, C.; Schneider, S.; Stoltefuss, J. Angew. Chem., Int. Ed. 1999, 38, 3373. Hexasubstituted arenes: (e) Kiprof, P.; Li, J.; Renish, C. L.; Kalombo, E. K.; Young, V. G. J. Organometallic Chem. 2001, 620(1-2), 113. (f) Brandenburg, J.; Beckert, R.; Fehling, P.; Doering, M.; Goeris, H. J. Prakt. Chem./Chem.Ztg. 1996, 338, 430.

3. (a) Hagemann, C. Ber. Dtsch. Chem. Ges. 1893, 26, 876. (b) Hagemann, C. Ber. Dtsch. Chem. Ges. 1893, 26, 2300.

4 Knoevenagel, E. Liebigs Ann. Chem. 1894, 281, 25.

5. (a) Rabe, P.; Rahn, R.; Elze, F. Liebigs Ann. Chem. 1904, 332, 1. (c) Rabe, P.; Spence, D. Liebigs Ann. Chem. 1905, 342, 328. (c) Dieckmann, W. Ber. 1912, 45, 2689. (e) Dieckmann, W. Ber. Dtsch. Chem. Ges. 1912, 45, 2967.

6. Hoye, T. R.; Magee, A. S.; Rosen, R. E. J. Org. Chem. 1984, 49, 3224. 
7. (a) Horning, E. C.; Denekas, M. O.; Field, R. F. J. Org. Chem. 1944, 9, 548. (b) Horning, E. C.; Field, R. E. J. Am. Chem. Soc. 1946, 68, 384.

8. Tietze, L. F.; Brashe, G.; Gericke, K. M. Domino Reactions in Organic Chemistry, WileyVCH, 2006, Weinhein.

9. (a) Aniliker, R.; Lindsey, A. S.; Nettelton, D. E., Jr.; Turner, R. B. J. Am Chem. Soc. 1957, 79, 220. (b) Mongrainn, M.; Lafontaine, J.; Belanger, A.; Deslonghamps, P. Can. J. Chem. 1970, 48, 3273. (c) McCurry, P. M., Jr.; Singh, R. K. Synth. Commun. 1976, 6, 75.

10. Pollini, G. P.; Benetti, S.; Risi, C. D.; Zanirato, V. Tetrahedron 2010, 66, 2775.

11. Smith, L. I. Rouault, G. F. J. Am. Chem. Soc. 1943, 65, 631.

12. (a) Hogg, J. A. J. Am. Chem. Soc. 1948, 70, 161. (b) Hogg, J. A. J. Am. Chem. Soc. 1949, 71, 1918. (c) Edgar, A. J. B.; Harper, S. H.; Kazi, M. A. J. Chem. Soc. 1957, 1837. (d) Marshall, J. A.; Cohen, N.; Hochstetler, A. R. J. Am. Chem. Soc. 1966, 88, 3408. (e) Nasipuri, D.; Sarkar, G.; Guha, M.; Roy, R. Tetrahedron Lett. 1966, 9, 927. (f) McAndrews, B. A. J. Chem. Soc., Perkin Trans. I. 1979, 7, 1837. (g) White, J. D.; Sung, W. L. J. Org. Chem. 1974, 39, 2323. (h) Ziegler, F. E.; Kloek, J. Tetrahedron, 1977, 33, 373. (i) Battiste, M. A.; Strekowski, L. Paryzek, Z. Org. Process. Res. Devel. 1977, 1, 222. (j) Sakan, K.; Smith, D. A.; Babirad, S. A.; Fronczek, F. R.; Houk, K. N. J. Org. Chem. 1991, 56, 2311.

13. Dyier, F. J.; Kidd, D. A. A.; Walker, J. J. Chem. Soc., Perkin Trans. 1 1952, 4778.

14. (a) Mosettig, E.; Duvall, H. M. J. Am. Chem. Soc. 1937, 59, 367. (b) Horning, E. C.; Horning, M. G. J. Am. Chem. Soc. 1947, 69, 1359. (c) Horning, E. C.; Horning, M. G.; Walker, G. N. J. Am. Chem. Soc. 1949, 71, 169.

15. (a) Tietze, L.; Kiedrowski, G.; Berger, B. Tetrahedron Lett. 1982, 23, 51. (b) Al-Hassan, M. I. Gazz. Chim. Ital. 1987, 117, 187. (c) Tamura, Y.; Yoshimoto, Y.; Suzuki, M.; Terashima, M. Chem. Ind. 1970, 1410. (d) Tamura, Y.; Yoshimoto, Y. Chem. Ind. 1980, 888.

16. Kotnis, A. S. Tetrahedron Lett. 1990, 31, 481.

17. Tarbell, D. S. Org. React. 1944, $2,1$.

18. (a) Sato, M.; Miyaura, N.; Suzuki, A. Chem. Lett. 1989, 1405. (b) Oh-e, T.; Miyaura, N.; Suzuki, A. Synlett 1990, 221.

19. Tsai, M.; Friend, C. M.; Muetterties, E. L. J. Am. Chem. Soc. 1982, 104, 2539.

20. Still, W. C.; Kahn, M.; Mitra, A. J. Org. Chem. 1978, 43, 2923. 